تأثير ابعاد زبرى ايجاد شده در وجه بالادست و ياييندست يايه بيل مربعى بر گودال آبشستگى

حسين كاظمىزاده'، مجتبى صانعى اوז" و هومن حاج كندى"

(تاريخ دريافت:

جكيده

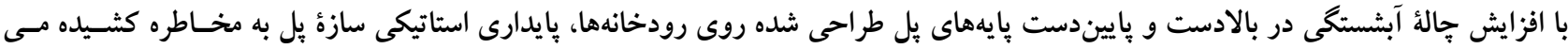

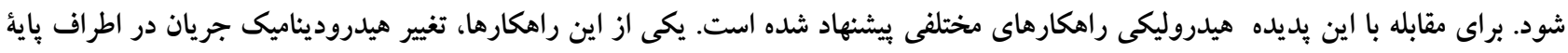

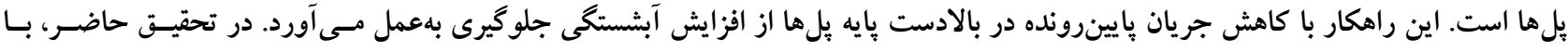

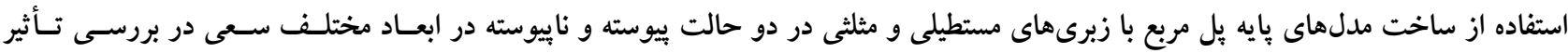

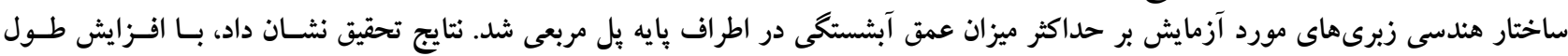

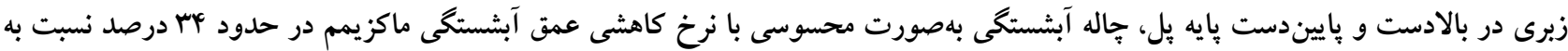

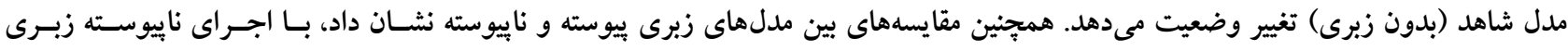

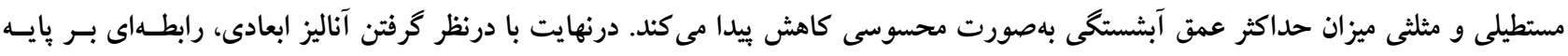

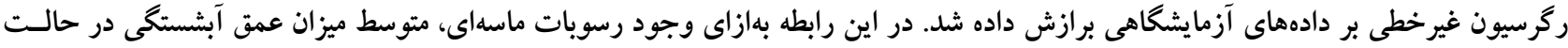

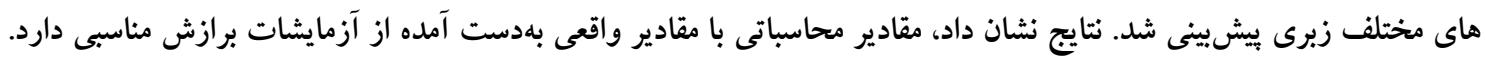

وازههاى كليدى: گودال آبشستخى، پايه يٍل مربعى، زبرى مستطيلى، زبرى مثلثى، رگرسيون غيرخطى، آناليز ابعادى

ا. كروه عمران آب، واحد نجف آباد، دانشخاه آزاد اسلامى، نجف آباد، ايران

r. يزؤهشكده حفاظت خاك و آبخيزدارى، دانشگاه تهران

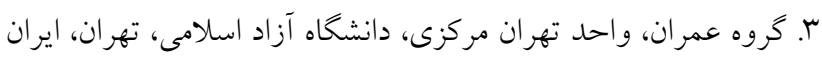

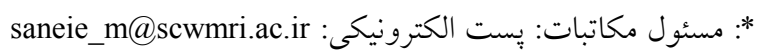


با اين حال بررسى در زمينه گروه يايهها كمتـر مـورد توجـهـ بوده است. بديدههاى مهمى كه بهدليل وجود گروه يايهها ايجـاد مىشوند عبارتاند از: بِديده حفاظ بــودن (Sheltering)، يديــه تقويت كننده (Reinforcing)، گــردابهــاى نعـل اسـبى بـهـــم فشـرده (Horse-shoe vortex compression) و خــــدابهـاى جارى (Shed vortices). تأثير يديدههاى فوق بـا تغييـر فاصـله

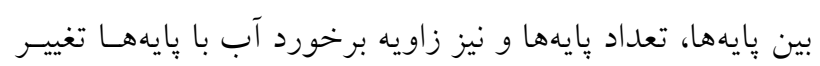

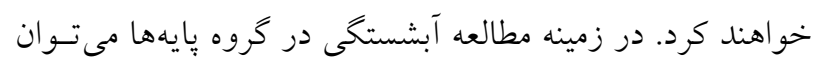
به مطالعات بايرام و لارسن (ه) و زراتى و همكاران (YY)، اتمـا و همكاران (11) و بهشتى و عطايى آشتيانى (V) اشاره كرد.

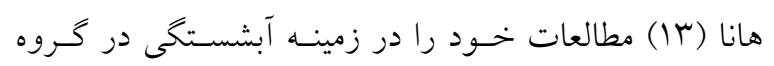
يايههاى دوتايى بــا اسـتفاده از بايـههــاى اسـتوانهاى در جريـان

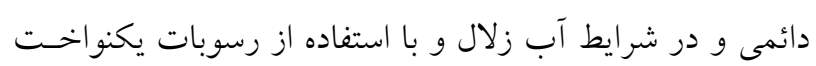
با قطر متوسط NA / ميلى متر انجام داد. آزمايشها در ابتدا بـراى تكىيايه استوانهاى انجام شد كه نتايج آن براى مقايسـه بـا گــروه يايهها بهكار رفـت. نتـايج نشـان داد، م^ درصــ عمـق متعـادل آبشستخى بعد از مدت V ساعت اتفاق مىافتد. از ايسنرو، تمـام آزمايشها در مدت V ساعت انجام شدند. سرعت برشى جريان در آزمايشها هانا VY درصد مقدار بحرانى آن در آستانه حركت

$$
\text { ذرات رسوب بود. }
$$

عطايى آشتيانى و بهشتى (ب)، آرايش متفاوت گروه يايهها را در شرايط آب زلال مورد بررسى قرار دادند. نتايج مطالعـه آنهـا

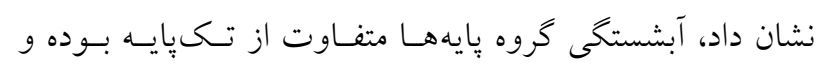

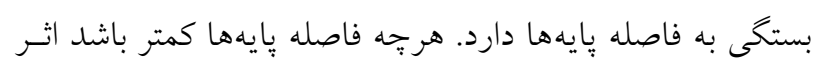
متقابل پايهها بيشتر شده و زمانى كه نسبت فاصله يايـه بـهـ قطـر

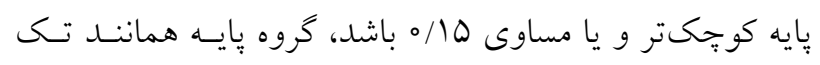

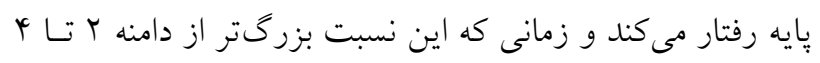

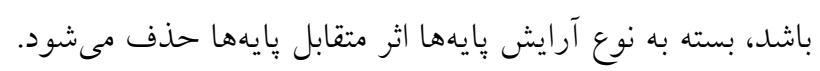

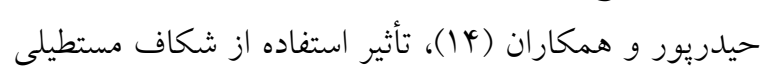
در كتترل و كـاهش آبشسـتخى موضعى در گروه يايههاى دو و سهتايى استوانهاى واقع در امتداد يك خط در شرايط آب زلال
ايجاد تأسيسات آبى در مجاورت رودخانهها از قبيل ايستخاههاى تأمين آب كشاورزى، شرب و ساحل سازى، ديوارههاى ساحلى،

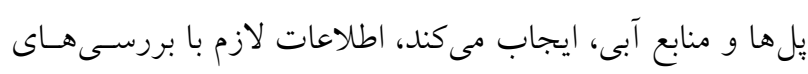

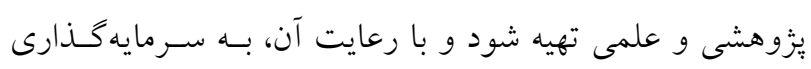

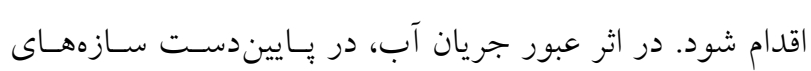

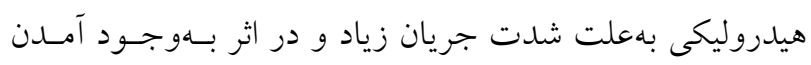
جريانهاى متلاطم موضعى، فرسايش بسـتر بـهورجـود مسى آيــد.

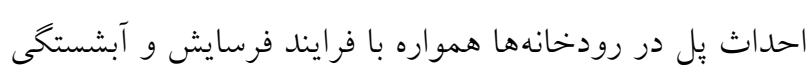
در يايه آن همراه است. برخورد خطوط جريان و جدايى آنهـا از

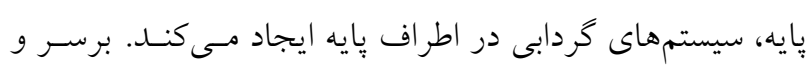

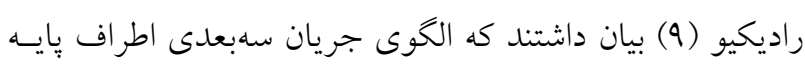
متشكل از جريان رو به بايين (Down flow) و دو نـوع سيستم

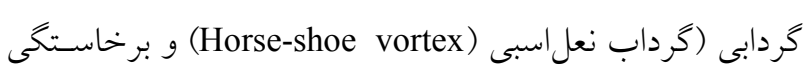
هستند. تاكنون اكثر يزوهشخران الكوى جريان در اطراف تكىپايهها را مورد مطالعه قرار دادهاند. كه بر اين اساس از نظـر ملويـل و جِيـو

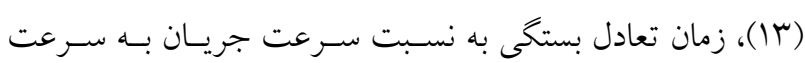
بحرانى $\frac{u}{u_{c}}$ عمق آبشستخى با استفاده از رابطه زير محاسبه مىشود. $\frac{\mathrm{d}_{\mathrm{s}}}{\mathrm{d}_{\mathrm{se}}}=\exp \left(-0.03\left|\frac{\mathrm{u}_{\mathrm{c}}}{\mathrm{u}} \ln \left(\frac{\mathrm{t}}{\mathrm{t}_{\mathrm{c}}}\right)\right|^{1.6}\right)$

همجنين نتايج اين تحقيق نشان مىدهد كه بعـد از كذشــت

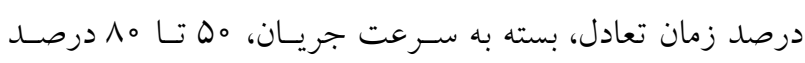
عمق متعادل آشستخى توسعه بيدا مى كند.

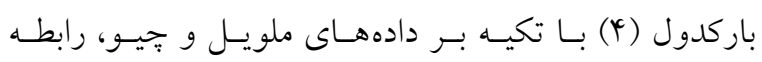
ركرسيونى زير رابراى تخمين عمق آبشستخى نسبت بـه زمـان ارائه كردند: - أنس

$\frac{\mathrm{d}_{\mathrm{s}}}{\mathrm{d}_{\mathrm{se}}}=\exp \left(-0.03\left|\frac{\mathrm{u}_{\mathrm{c}}}{\mathrm{u}} \ln \left(\frac{\mathrm{t}}{\mathrm{t}_{\mathrm{c}}}\right)\right|\right)$

كه در اين روابط ds عمـق آبشســـى در هـر لحظـه، dse عمـق آبشستخى نهايى، Uuc سرعت بحرانى، U سرعت متوسط، th زمـان، 
كـرده و به تـأخير مى اندازد ولى، درصورت توسعه آبشستخى به

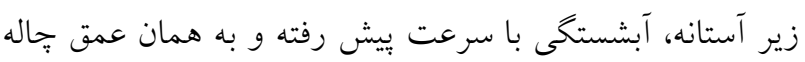

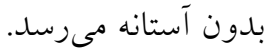

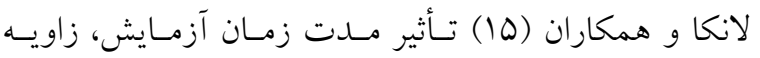

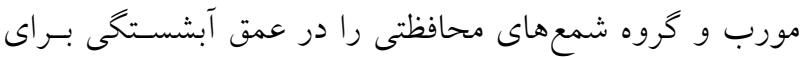

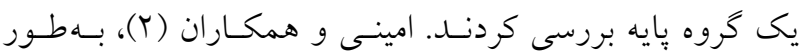

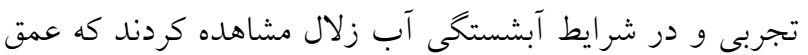

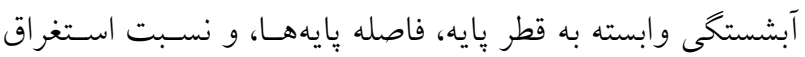

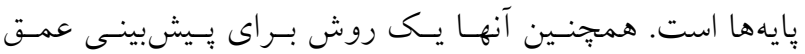

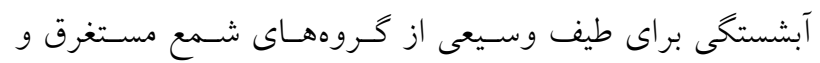
غير مستغرق توسعه دادند.

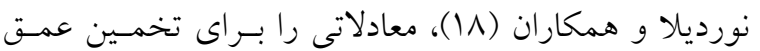

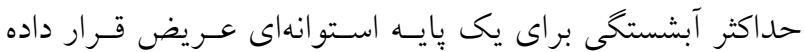
شده در رسوب يكنواخت ييشنهاد كردند. بهشتى و آشتيانى (9)،

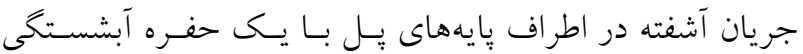
توسعه يافته را توسط اندازهيرى سـرعت لحظـهاى بـا اسـتفاده

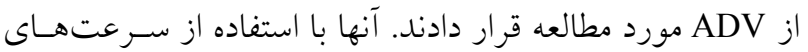

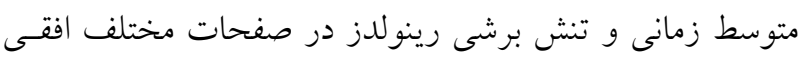

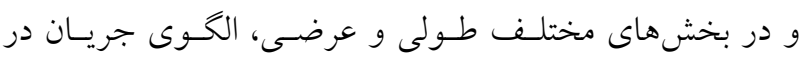
اطر اف بِايههاى بِ بل را بررسى كردند.

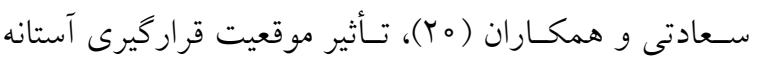

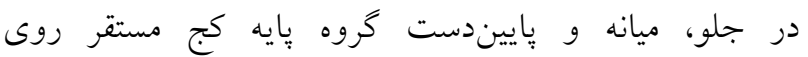
فونداسـيون مستطيلى كـه در ترازهـاى مختلـف نسبت به بستر

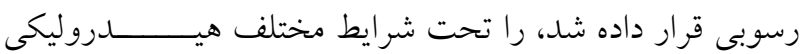
مــورد بررســـى قرار دادنـــــ مقايسه نتايج نشان داد كه از ميان

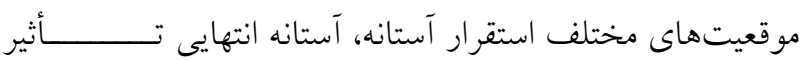
معنىدارى بر كاهش آبشستىى در ترازهاى مختلف كاركذارى فونداسيون، سرعتهاى نسبى و عمق جريان نداشت. تجزيــه و

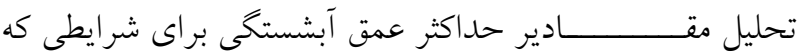

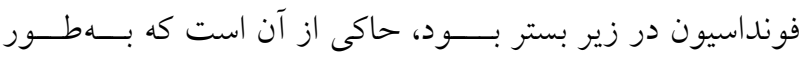

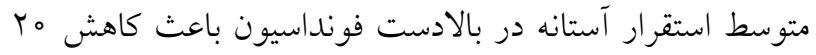
درصدى و كار گذارى آن در قــسمت ميانى منجر به كاهش بـ بـ 19

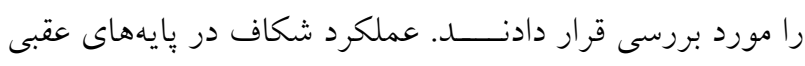
كروه بايههاى دو و سه تايى با فاصله جهار برابر قطر بايه بيشتر

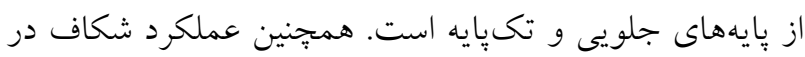

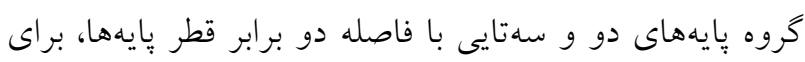

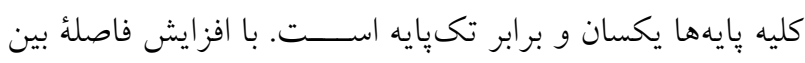

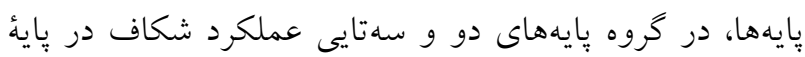

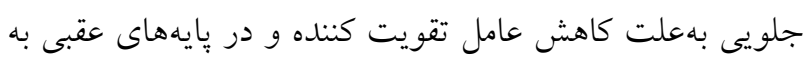
علت كاهش تأثير گردابهاى جارى، افزايش مىيابد.

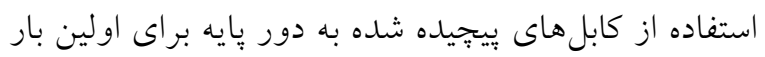

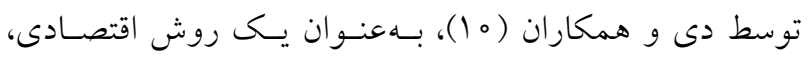

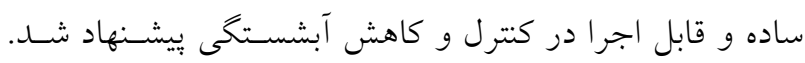
در اين روش كابل بهصورت حلزونى به دور پايه يِيجيده شده

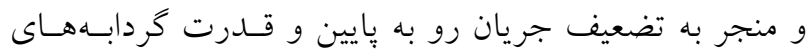

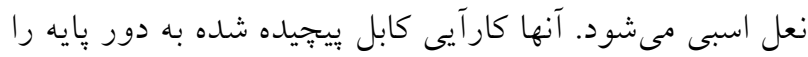

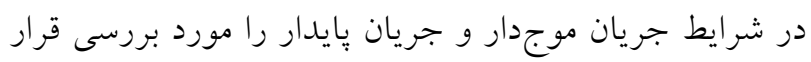

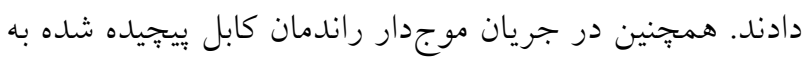

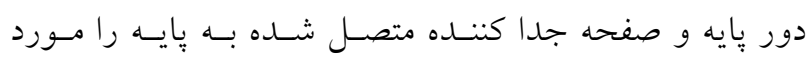

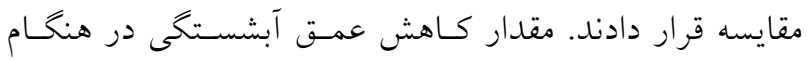

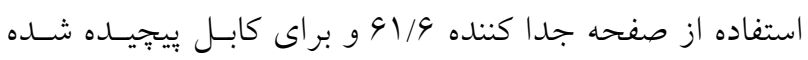

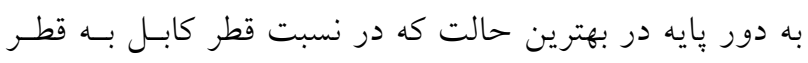

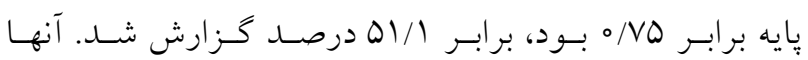

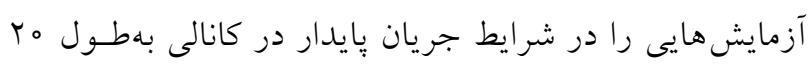

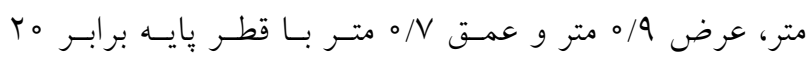

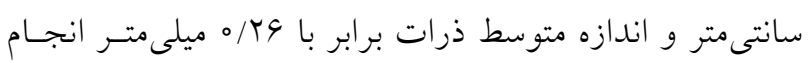

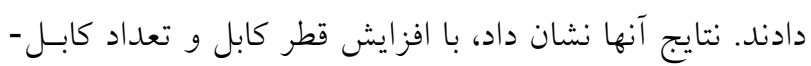

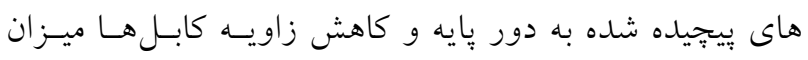

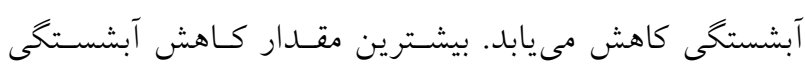

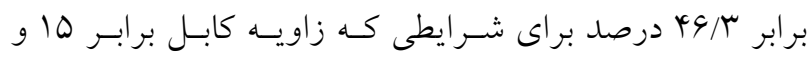
نسبت قطر كابل به پايه برابر //ه است گزارش شد.

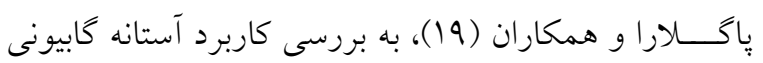

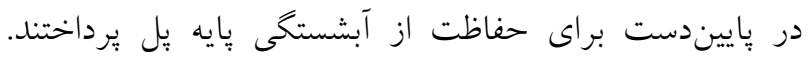

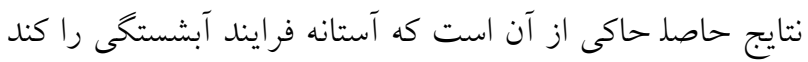


روى بايههاى بل متوالى برداختند. نتايج اين تحقيق نشان داد كه

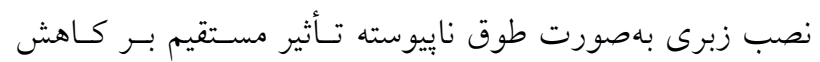

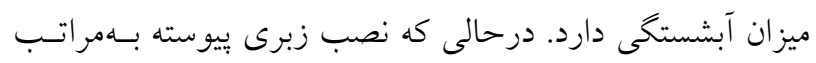

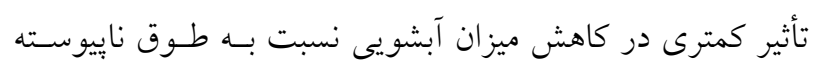

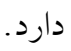

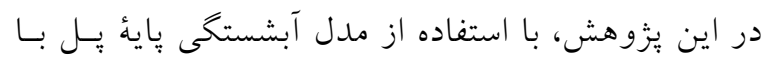

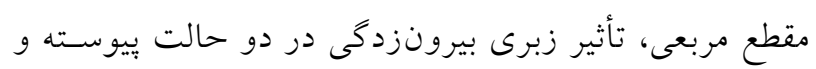

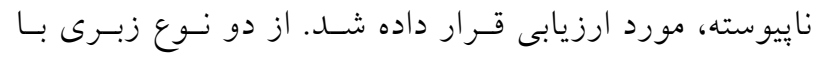

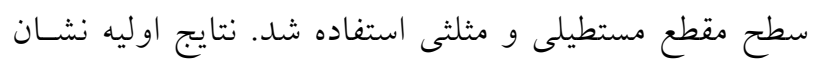

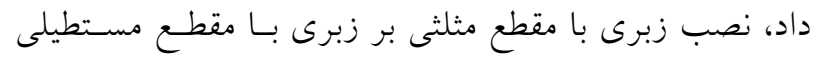

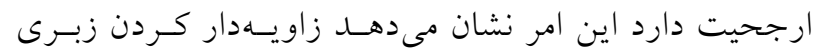

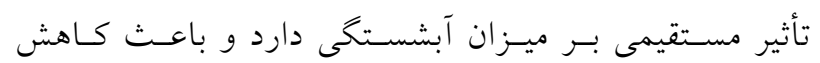

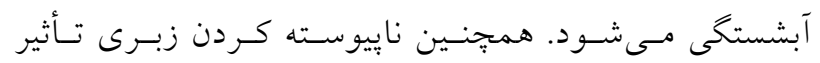

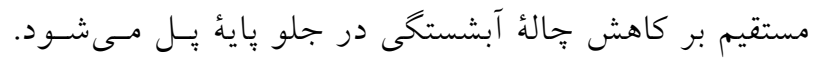

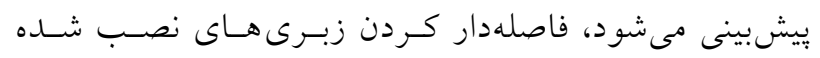

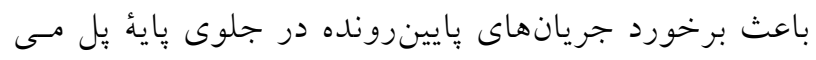

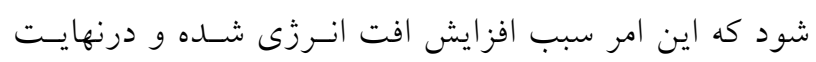
كاهش آبشستخى مى شودد.

\section{مواد و روشها تجهيزات آزمايشخاهى}

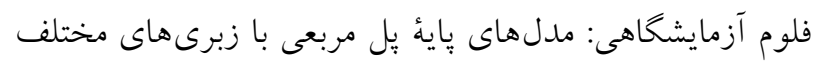

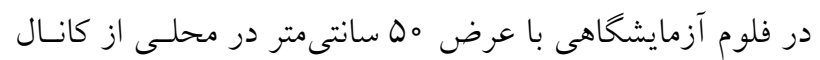

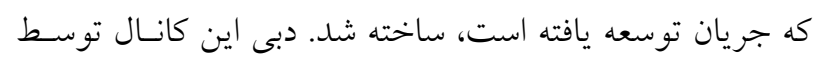

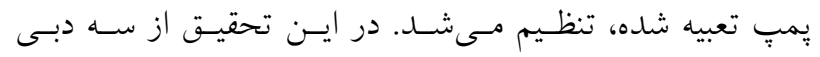

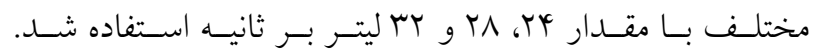

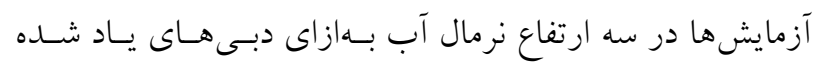

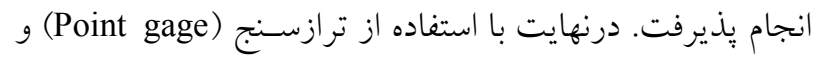

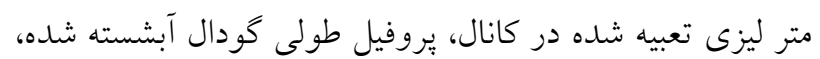

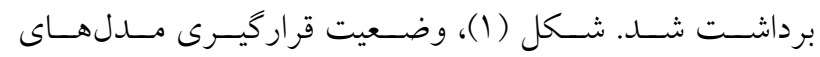

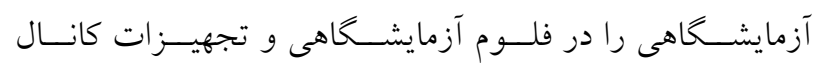

$$
\text { درصد آبشستخى مى شود. }
$$

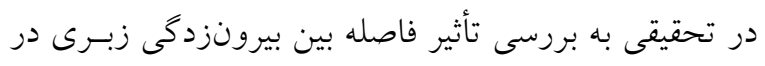

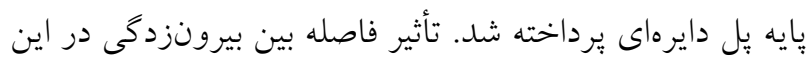

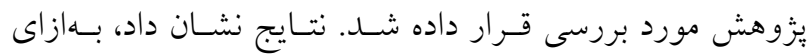

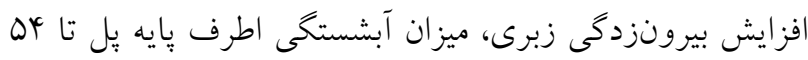

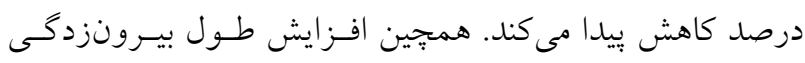

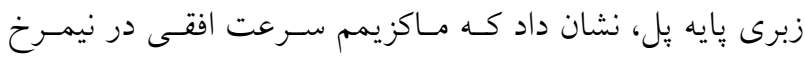

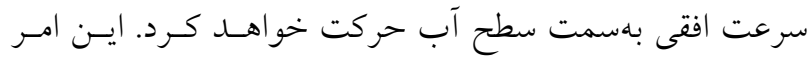
باعث مى شود كه سرعت برشى نسبت به سرعت بحرانى ذرات

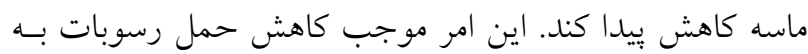

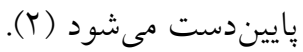
در تحقيقى اثر طوق نصب شده در اطــراف يايسه بــل مـورد

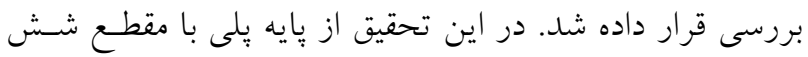

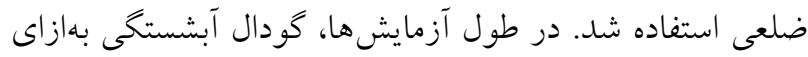

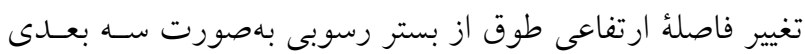

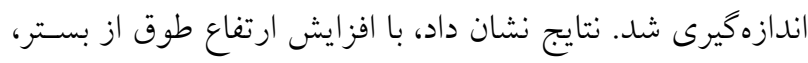

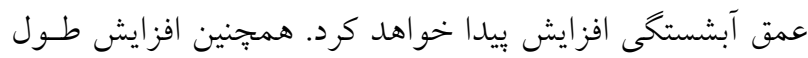

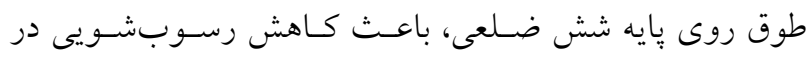

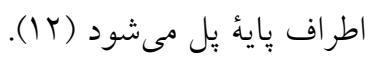

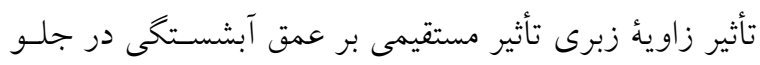

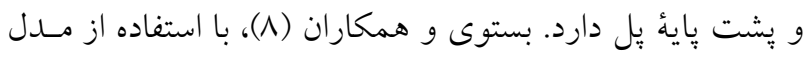

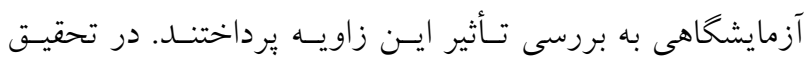

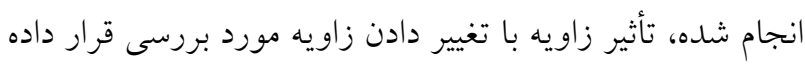

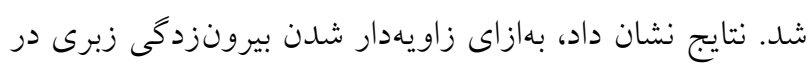

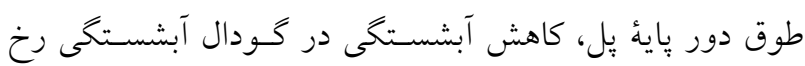

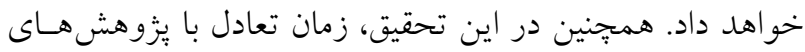

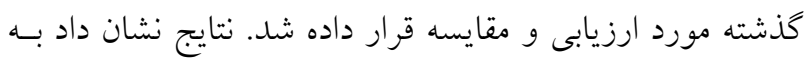

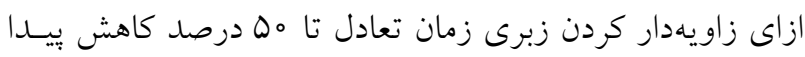
خواهد كرد. از اينرو زاويهدار كردن زبرى مسى توانــ زمـان بــهـ

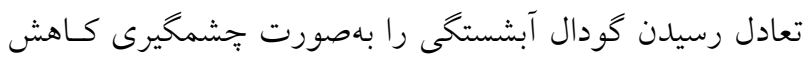

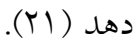
ممار و همكاران (IV)، به بررسى تأثير زبــرى نصـب شـاهـ 


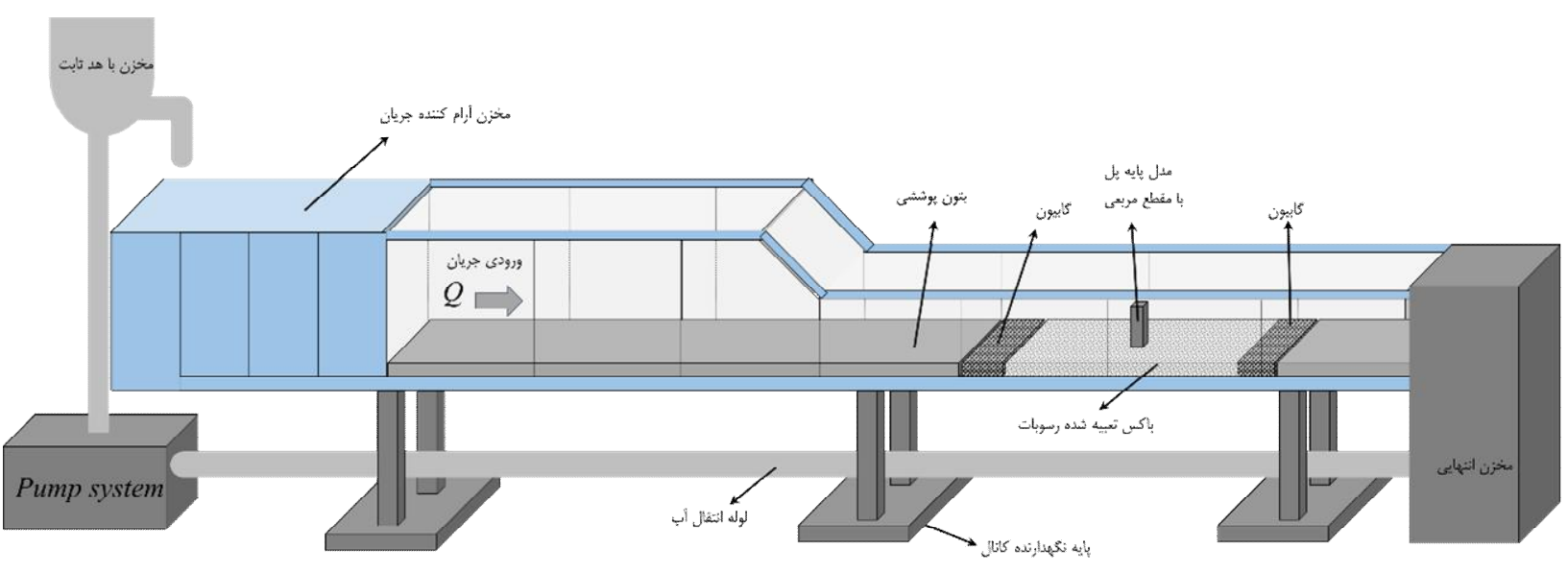

شكل 1. كانال آزمايشعاهى و تجهيزات آن

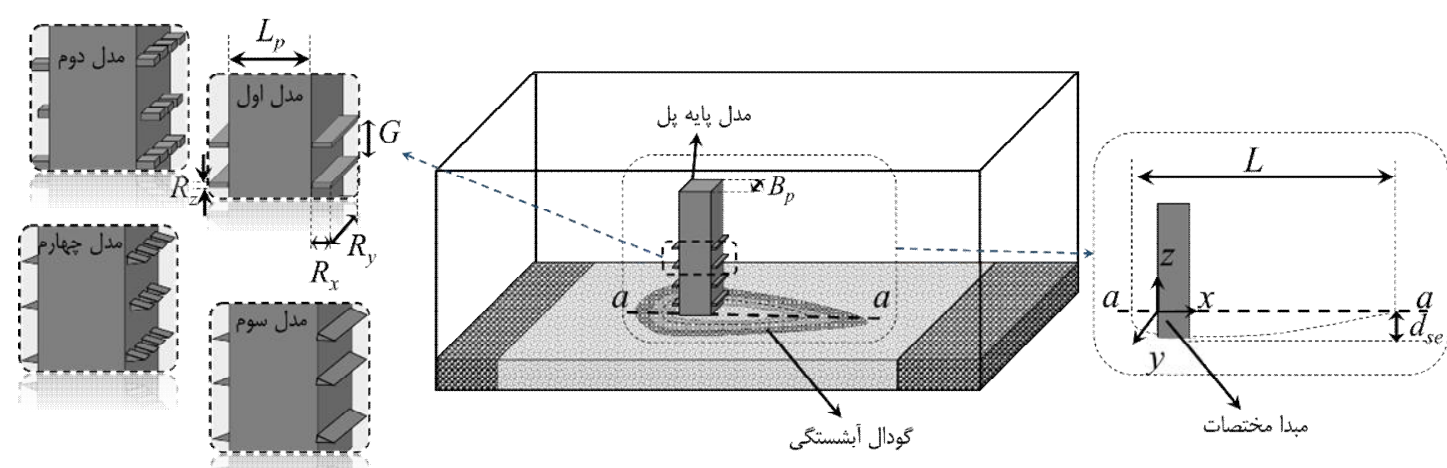

شكل r. موقعيت قراركيرى مدل آزمايشحاهى در كانال همر اه با بارامترهاى فيزيكى مدل زبرى بائه بِل و مبدأ مختصات

داده شده است. نقطه بالادست مدل بِيسه هـل مربعسى در سـطح

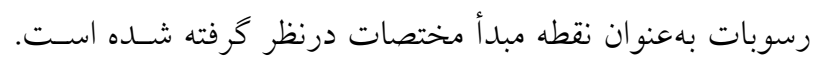

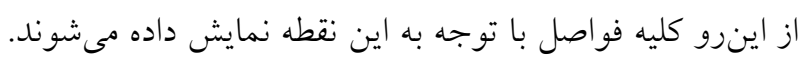

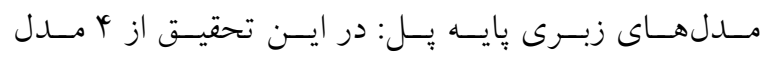

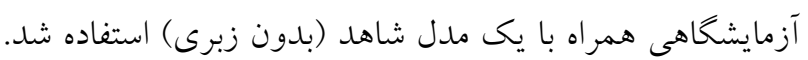

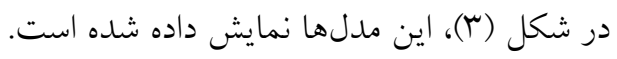

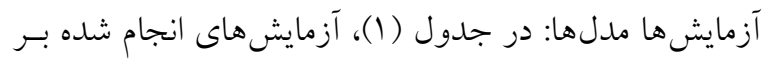

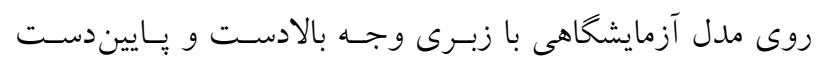

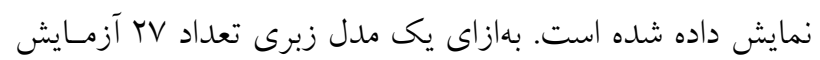

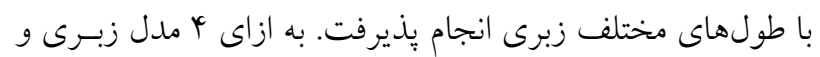

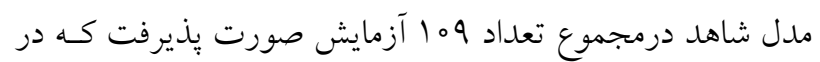

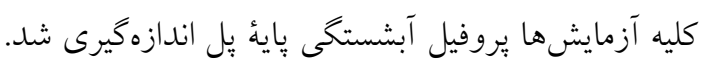

آزمايشكاهى را نمايش مىدهد. جعبه رسوبات: در جهت كاهش ميزان حجم رسوبات بـراى مهاى

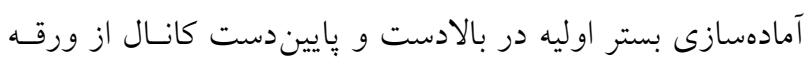

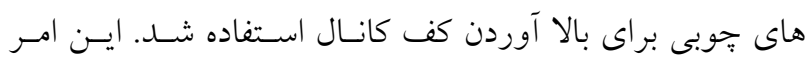
موجب مىشود كه حجم رسوبات استفاده شده كاهش بيدا كند. همجنين با توجه به نظر ملوين و جيو (19)، در رسوبات رسوبات جريان

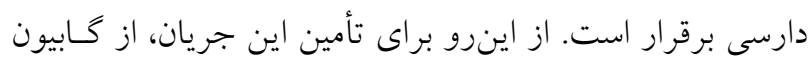

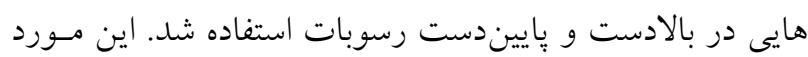
در شكل (1)، مشخص شده است.

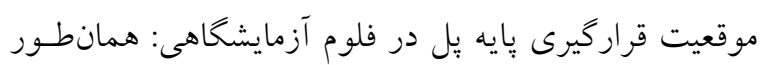

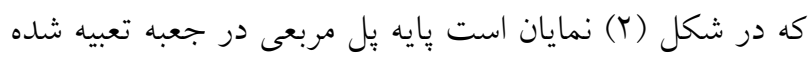

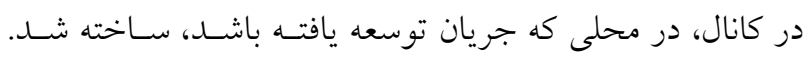

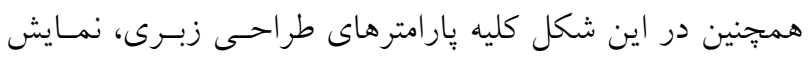




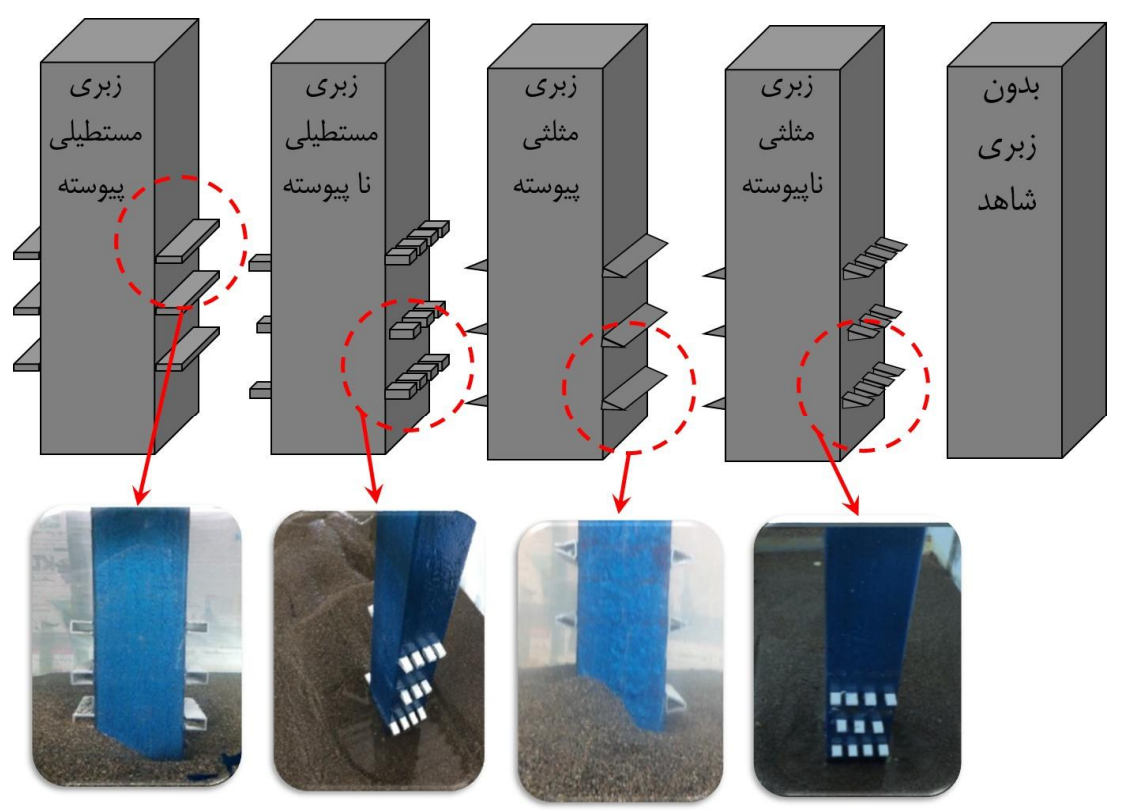

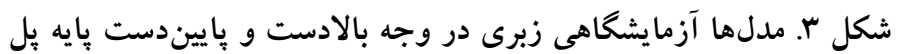

جدول ا. آزمايشهاى مدل زبرى بايه يل مربعى

\begin{tabular}{|c|c|c|c|c|c|c|c|c|c|c|}
\hline \multirow{2}{*}{$\begin{array}{c}\text { فاصله زبرى } \\
\text { (mm) } \\
\text { G }\end{array}$} & \multicolumn{3}{|c|}{ ابعاد زبرى (mm) } & \multirow{2}{*}{ نوع زبرى } & \multirow{2}{*}{$\begin{array}{c}\text { عرض يايه } \\
\text { (mm) } \\
\text { Bp }\end{array}$} & \multirow{2}{*}{$\begin{array}{c}\text { طول يايه } \\
(\mathrm{mm}) \\
\text { L }\end{array}$} & \multirow{2}{*}{$\begin{array}{c}\text { عرض كانال } \\
\text { (mm) } \\
\text { B }\end{array}$} & \multirow{2}{*}{$\begin{array}{c}\text { عمق آب } \\
\text { (mm) } \\
\text { y }\end{array}$} & \multirow{2}{*}{$\begin{array}{c}\text { دبى } \\
(\mathrm{L} / \mathrm{s}) \\
\mathrm{Q}\end{array}$} & \multirow{2}{*}{ شماره } \\
\hline & $\begin{array}{l}\text { ارتفاع } \\
\text { (Rz) }\end{array}$ & $\begin{array}{l}\text { عرض } \\
\text { (Ry) }\end{array}$ & $\begin{array}{l}\text { طول } \\
\text { (Rx) }\end{array}$ & & & & & & & \\
\hline$\omega_{0}$ & 10 & $10 \circ$ & IV & & 100 & 100 & Q०० & $110^{\circ}$ & TY & 1 \\
\hline Q. & 10 & 100 & ro & ع، r، r، ا، شاهد & 100 & 100 & Q०० & Yoo & rA & r \\
\hline$\omega_{0}$ & 10 & $10 \circ$ & $\Delta Y$ & ع با، r، 1، شاهد & 100 & 100 & ఎ०० & rlo & re & r \\
\hline$V_{0}$ & 10 & 100 & IV & & $10 \circ$ & $10 \circ$ & Q०० & 110 & TY & $r$ \\
\hline$v_{0}$ & 10 & 100 & ro & ع r، rا، ا، شاهد & 100 & 100 & Q.० & roo & YA & 0 \\
\hline$v_{0}$ & 10 & 100 & $\Delta Y$ & ع ب، rا، ا، شاهد & 100 & 100 & ఎ०० & rlo & re & 9 \\
\hline$v_{0}$ & 10 & 100 & IV & عَr r، r، ا، شاهد & 100 & 100 & Q०० & 110 & TY & v \\
\hline 90 & 10 & 100 & ro & ع r، rا، 1، شاهد & 100 & 100 & Q.०० & roo & rA & $\wedge$ \\
\hline 90 & 10 & 100 & $\Delta T$ & 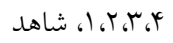 & 100 & 100 & Q०० & rlo & rt & 9 \\
\hline$\omega_{0}$ & 10 & 100 & IV & & $10 \circ$ & $10 \circ$ & Q०० & 110 & TY & 10 \\
\hline Q. & 10 & 100 & ro & ع r، r، 1، شاهد & 100 & 100 & Q.० & roo & rA & 11 \\
\hline ఎ. & 10 & $10 \circ$ & $\Delta r$ & ع ب، rا، 1، شاهد & $10 \circ$ & 100 & Q०० & rlo & rT & ir \\
\hline$v_{0}$ & 10 & 100 & IV & ع، r، ז، ا، شاهد & 100 & 100 & Q.०० & 110 & TY & ir \\
\hline vo & 10 & 100 & ro & ץ، r، ז، ا، شاهد & 100 & 100 & Q.० & roo & rA & 14 \\
\hline$v_{0}$ & 10 & $10 \circ$ & $\Delta T$ & ץ، r، T، ا، شاهد & 100 & 100 & Q०० & rlo & re & 10 \\
\hline$V_{0}$ & 10 & $10 \circ$ & IV & ז'، r، r، ا، شاهد & $10 \circ$ & $10 \circ$ & Q०० & 110 & TY & 19 \\
\hline 90 & 10 & 100 & ro & ع، r، r، 1، شاهد & 100 & 100 & Q.० & roo & rA & IV \\
\hline 90 & 10 & $10 \circ$ & $\Delta T$ & ץ، ז، ז، ا، شاهد & 100 & 100 & Q०० & rlo & rT & 11 \\
\hline$\omega_{0}$ & 10 & $10 \circ$ & IV & ז'، r، r، ا، شاهد & $10 \circ$ & $10 \circ$ & Q०० & 110 & TY & 19 \\
\hline Q. & 10 & 100 & ro & ع، r، r، ا، شاهد & 100 & 100 & Q.० & roo & $r \Lambda$ & ro \\
\hline Q. & 10 & 100 & $\Delta T$ & ع، r، ז، ا، شاهد & 100 & $10 \circ$ & Q.०० & rlo & ru & rI \\
\hline$V_{0}$ & 10 & 100 & IV & ז'، r، r، ا، شاهد & $10 \circ$ & $10 \circ$ & Q.० & 110 & YY & Tr \\
\hline$v_{0}$ & 10 & 100 & ro & ץ، r، ז، ا، شاهد & $10 \circ$ & 100 & Q०० & roo & $r \Lambda$ & זr \\
\hline$v_{0}$ & 10 & 100 & $\Delta T$ & ع، r، ז، ا، شاهد & 100 & 100 & Q.० & rlo & rT & TY \\
\hline$V_{0}$ & 10 & $10 \circ$ & IV & ז'، r، r، ا، شاهد & $10 \circ$ & $10 \circ$ & Q.० & 110 & YY & ro \\
\hline 90 & 10 & 100 & ro & ץ، r، ז، ا، شاهد & 100 & 100 & Q.० & roo & $r \Lambda$ & rq \\
\hline 90 & 10 & 100 & $\Delta Y$ & 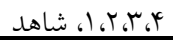 & 100 & 100 & $0 \circ \circ$ & rlo & Mr & TV \\
\hline
\end{tabular}




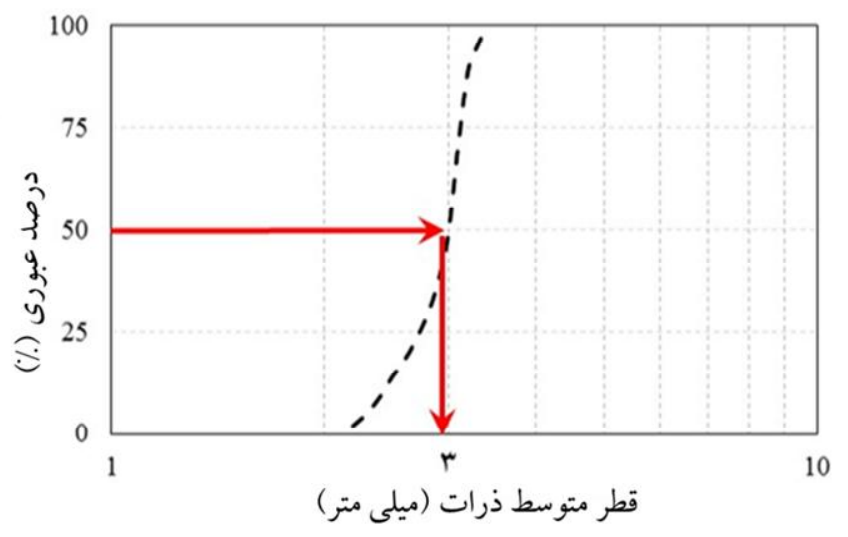

شكل fا. دانهبندى خاك استفاده شده

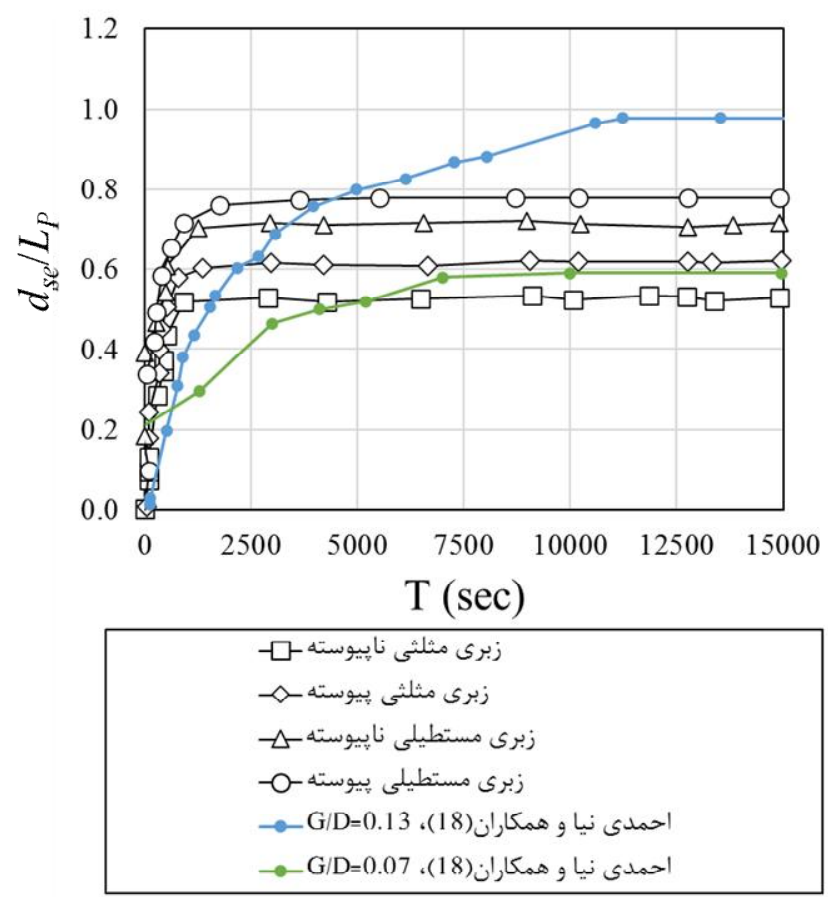

شكل ه. زمان تعادل آبشستخى آزمايشهاى مدل زبرى

آزمايشهاى انجام شده در جدول (1)، نمايش داده مىشـود. در

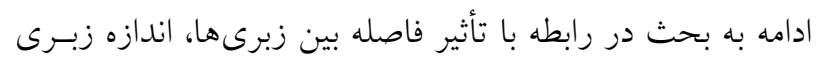
ها و همجنين بيوستخى و عدم بيوستخى زبرىهاى استفاده شده

$$
\text { برداخته مىشود. }
$$

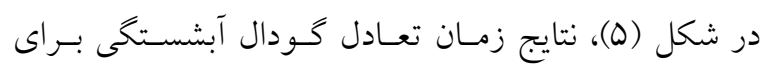

مدلهاى زبرى نمايش داده شده است. در اين شـكل، از نسـبت

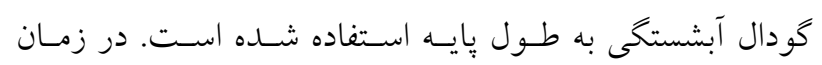

رسوبات استفاده شده: در شكل (Y)، منحنى دانهبندى رسـوبات نمايش داده شده است. همانطور كـه در شـكل مشـخص قطـر متوسط رسوبات در حدود r/9 ميلىمتر و ماسـه متوسـط دسـهـ بندى مىشود.

\section{نتايج و بحث}

در اين بخش، ابتدا يروفيل آبشستكى در مقطع بيشينه با توجه به 

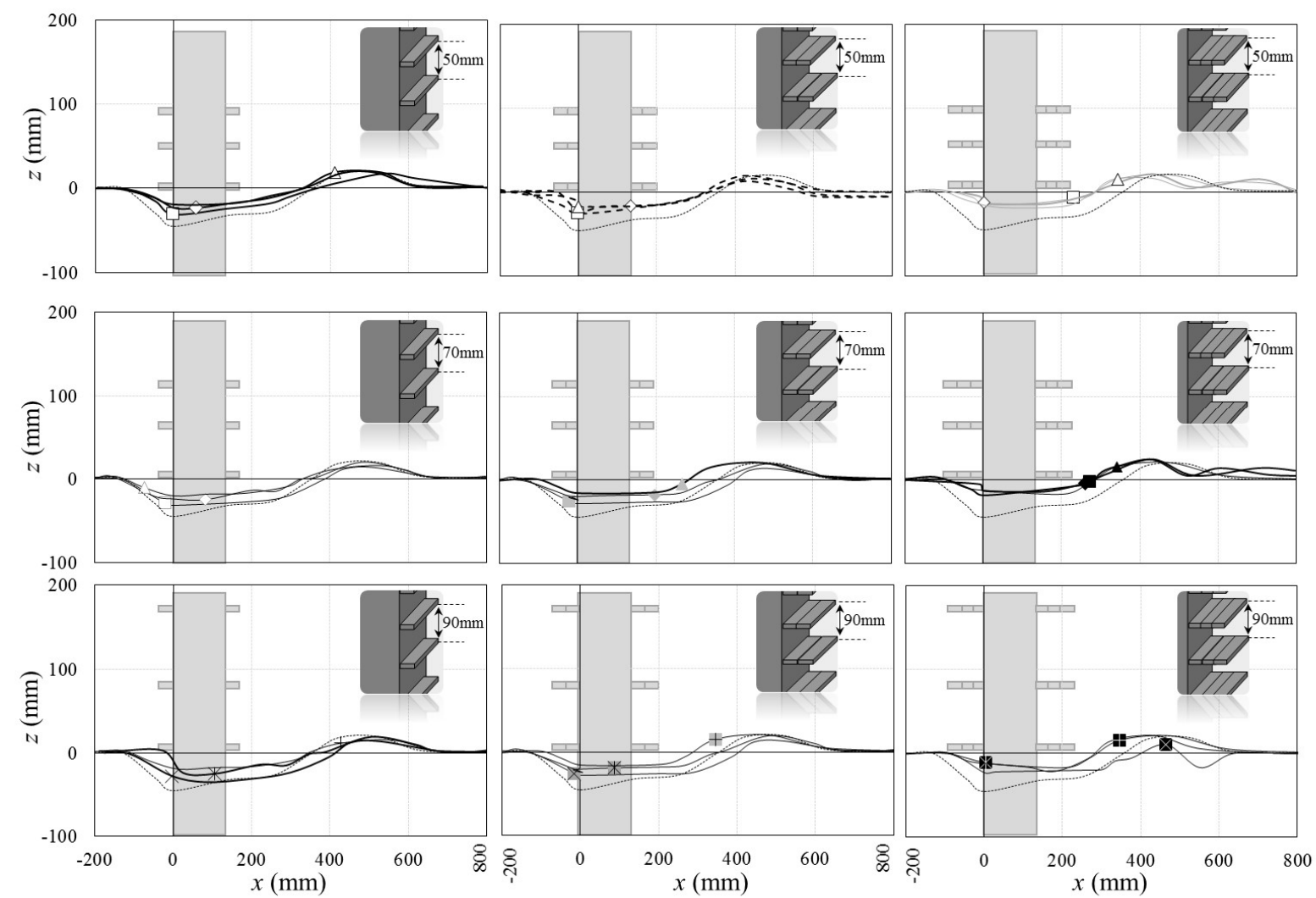

$-\square-\mathrm{G}=50 \mathrm{~mm}, \mathrm{yn}=180 \mathrm{~mm}, \mathrm{Rx}=17 \mathrm{~mm}$
$-\square-\mathrm{G}=50 \mathrm{~mm}, \mathrm{yn}=180 \mathrm{~mm}, \mathrm{Rx}=35 \mathrm{~mm}$
$\checkmark-\mathrm{G}=50 \mathrm{~mm}, \mathrm{yn}=200 \mathrm{~mm}, \mathrm{Rx}=52 \mathrm{~mm}$
$-\mathrm{G}=70 \mathrm{~mm}, \mathrm{yn}=200 \mathrm{~mm}, \mathrm{Rx}=17 \mathrm{~mm}$
$-\mathrm{G}=70 \mathrm{~mm}, \mathrm{yn}=200 \mathrm{~mm}, \mathrm{Rx}=35 \mathrm{~mm}$
$-\mathrm{G}=70 \mathrm{~mm}, \mathrm{yn}=200 \mathrm{~mm}, \mathrm{Rx}=52 \mathrm{~mm}$
$-\mathrm{G}=90 \mathrm{~mm}, \mathrm{yn}=200 \mathrm{~mm}, \mathrm{Rx}=17 \mathrm{~mm}$
$-\mathrm{G}=90 \mathrm{~mm}, \mathrm{yn}=200 \mathrm{~mm}, \mathrm{Rx}=35 \mathrm{~mm}$
$-\mathrm{G}=90 \mathrm{~mm}, \mathrm{yn}=200 \mathrm{~mm}, \mathrm{Rx}=52 \mathrm{~mm}$

$\checkmark-\mathrm{G}=50 \mathrm{~mm}, \mathrm{yn}=200 \mathrm{~mm}, \mathrm{Rx}=17 \mathrm{~mm}$ $-\diamond \mathrm{G}=50 \mathrm{~mm}, \mathrm{yn}=200 \mathrm{~mm}, \mathrm{Rx}=35 \mathrm{~mm}$ $\triangle \mathrm{G}=50 \mathrm{~mm}, \mathrm{yn}=210 \mathrm{~mm}, \mathrm{Rx}=52 \mathrm{~mm}$ $--\mathrm{G}=70 \mathrm{~mm}, \mathrm{yn}=210 \mathrm{~mm}, \mathrm{Rx}=17 \mathrm{~mm}$ $--\mathrm{G}=70 \mathrm{~mm}, \mathrm{yn}=210 \mathrm{~mm}, \mathrm{Rx}=35 \mathrm{~mm}$

$\triangle \mathrm{G}=70 \mathrm{~mm}, \mathrm{yn}=210 \mathrm{~mm}, \mathrm{Rx}=52 \mathrm{~mm}$ $+\mathrm{G}=90 \mathrm{~mm}, \mathrm{yn}=210 \mathrm{~mm}, \mathrm{Rx}=17 \mathrm{~mm}$ \# $\mathrm{G}=90 \mathrm{~mm}, \mathrm{yn}=210 \mathrm{~mm}, \mathrm{Rx}=35 \mathrm{~mm}$ \#- $\mathrm{G}=90 \mathrm{~mm}, \mathrm{yn}=210 \mathrm{~mm}, \mathrm{Rx}=52 \mathrm{~mm}$
$\neg-\mathrm{G}=50 \mathrm{~mm}, \mathrm{yn}=210 \mathrm{~mm}, \mathrm{Rx}=17 \mathrm{~mm}$ $-\square-\mathrm{G}=50 \mathrm{~mm}, \mathrm{yn}=180 \mathrm{~mm}, \mathrm{Rx}=52 \mathrm{~mm}$ $--\mathrm{G}=70 \mathrm{~mm}, \mathrm{yn}=180 \mathrm{~mm}, \mathrm{Rx}=17 \mathrm{~mm}$ $-\mathrm{G}=70 \mathrm{~mm}, \mathrm{yn}=180 \mathrm{~mm}, \mathrm{Rx}=35 \mathrm{~mm}$ $\rightarrow-\mathrm{G}=70 \mathrm{~mm}, \mathrm{yn}=180 \mathrm{~mm}, \mathrm{Rx}=52 \mathrm{~mm}$ $* \mathrm{G}=90 \mathrm{~mm}, \mathrm{yn}=180 \mathrm{~mm}, \mathrm{Rx}=17 \mathrm{~mm}$ $-x-G=90 \mathrm{~mm}, y n=180 \mathrm{~mm}, \mathrm{Rx}=35 \mathrm{~mm}$

$\forall-\mathrm{G}=90 \mathrm{~mm}, \mathrm{yn}=180 \mathrm{~mm}, \mathrm{Rx}=52 \mathrm{~mm}$ $\mathrm{G}=\mathrm{N} / \mathrm{A}, \mathrm{Rx}=\mathrm{N} / \mathrm{A}$

\section{شكل و. يروفيل آبشستخى مدل بايه بِل مربعى با زبرى مستطيلى ييوسته}

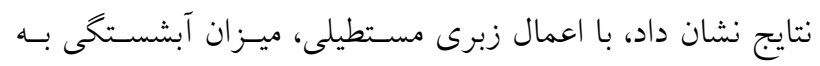

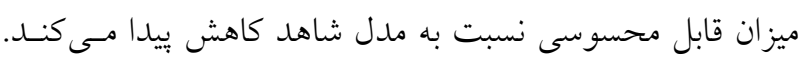

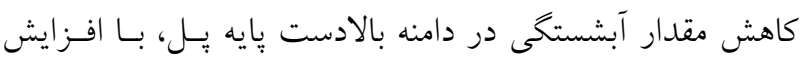

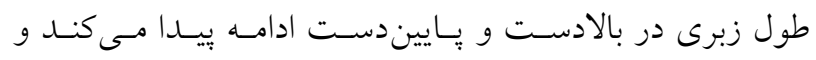

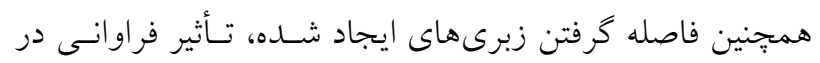

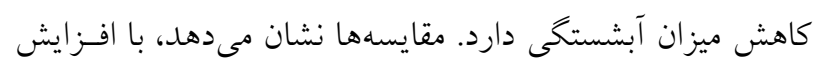

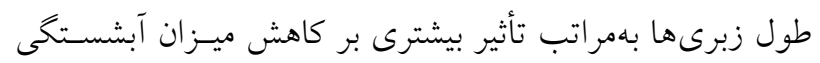

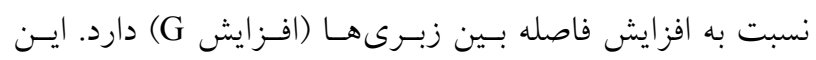

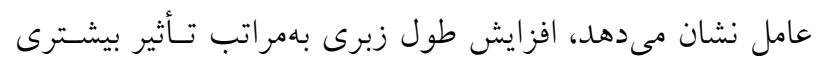

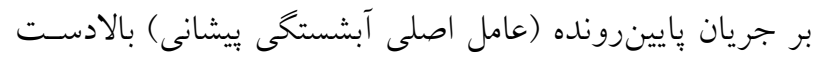

تقريبى يكى ساعت بروفيل آبشستخى به حالت تعادل رسسيد. در

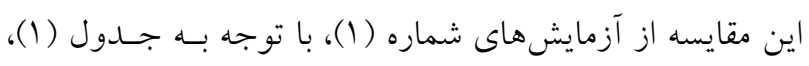

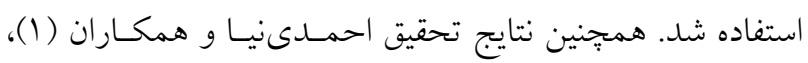
در شكل نمايش داده شده است.

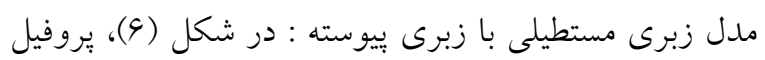

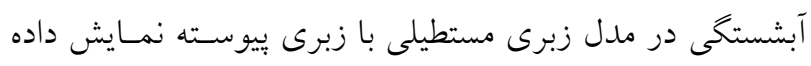

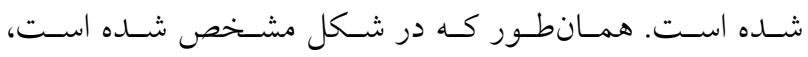

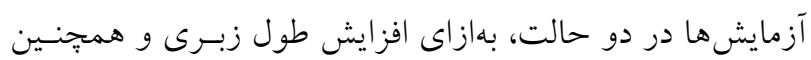

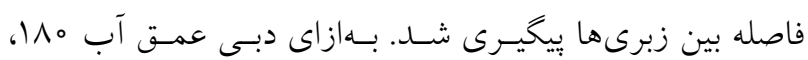

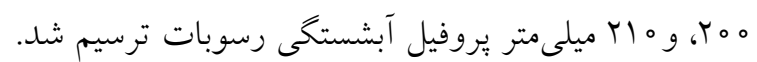



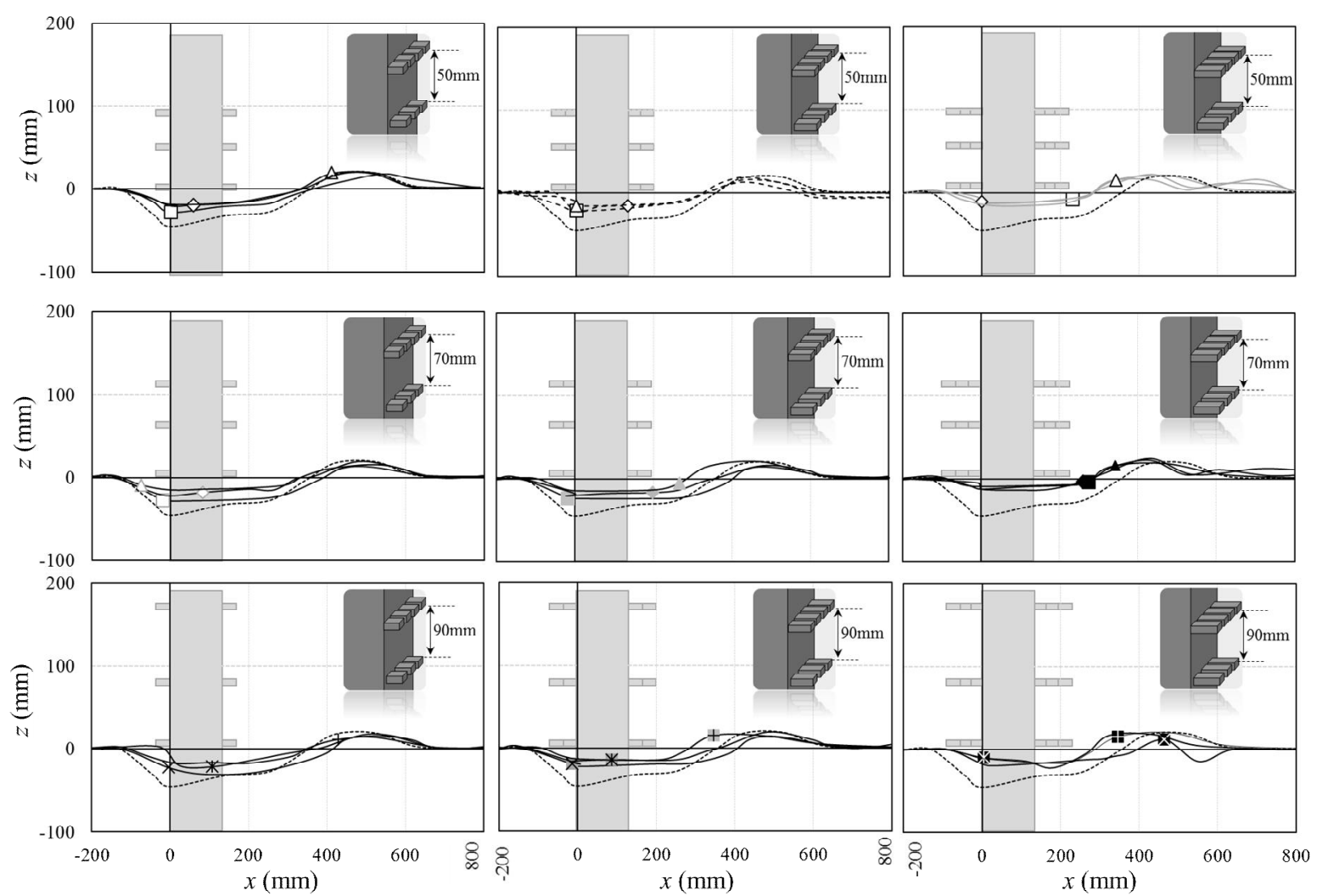

$-\square-G-50 \mathrm{~mm}, \mathrm{yn}-180 \mathrm{~mm}, \mathrm{Rx}-17 \mathrm{~mm}$
$-\square-\mathrm{G}=50 \mathrm{~mm}, \mathrm{yn}=180 \mathrm{~mm}, \mathrm{Rx}=35 \mathrm{~mm}$
$\diamond \mathrm{G}=50 \mathrm{~mm}, \mathrm{yn}=200 \mathrm{~mm}, \mathrm{Rx}=52 \mathrm{~mm}$
$--\mathrm{G}=70 \mathrm{~mm}, \mathrm{yn}=200 \mathrm{~mm}, \mathrm{Rx}=17 \mathrm{~mm}$
$--\mathrm{G}=70 \mathrm{~mm}, \mathrm{yn}=200 \mathrm{~mm}, \mathrm{Rx}=35 \mathrm{~mm}$
$-\mathrm{G}=70 \mathrm{~mm}, \mathrm{yn}=200 \mathrm{~mm}, \mathrm{Rx}=52 \mathrm{~mm}$
$*-\mathrm{G}=90 \mathrm{~mm}, \mathrm{yn}=200 \mathrm{~mm}, \mathrm{Rx}=17 \mathrm{~mm}$
$* \mathrm{G}=90 \mathrm{~mm}, \mathrm{yn}=200 \mathrm{~mm}, \mathrm{Rx}=35 \mathrm{~mm}$
$\rightarrow-\mathrm{G}=90 \mathrm{~mm}, \mathrm{yn}=200 \mathrm{~mm}, \mathrm{Rx}=52 \mathrm{~mm}$

$\leadsto-\mathrm{G}-50 \mathrm{~mm}, \mathrm{yn}-200 \mathrm{~mm}, \mathrm{Rx}-17 \mathrm{~mm}$

$-\diamond-\mathrm{G}=50 \mathrm{~mm}, \mathrm{yn}=200 \mathrm{~mm}, \mathrm{Rx}=35 \mathrm{~mm}$

$\triangle \mathrm{G}=50 \mathrm{~mm}, \mathrm{yn}=210 \mathrm{~mm}, \mathrm{Rx}=52 \mathrm{~mm}$

$-\mathrm{G}=70 \mathrm{~mm}, \mathrm{yn}=210 \mathrm{~mm}, \mathrm{Rx}=17 \mathrm{~mm}$

$-\mathrm{G}=70 \mathrm{~mm}, \mathrm{yn}=210 \mathrm{~mm}, \mathrm{Rx}=35 \mathrm{~mm}$

$\leftarrow \mathrm{G}=70 \mathrm{~mm}, \mathrm{yn}=210 \mathrm{~mm}, \mathrm{Rx}=52 \mathrm{~mm}$

+ $\mathrm{G}=90 \mathrm{~mm}, \mathrm{yn}=210 \mathrm{~mm}, \mathrm{Rx}=17 \mathrm{~mm}$

I $-\mathrm{G}=90 \mathrm{~mm}, \mathrm{yn}=210 \mathrm{~mm}, \mathrm{Rx}=35 \mathrm{~mm}$

- $-\mathrm{G}=90 \mathrm{~mm}, \mathrm{yn}=210 \mathrm{~mm}, \mathrm{Rx}=52 \mathrm{~mm}$
$\triangle-\mathrm{G}-50 \mathrm{~mm}, \mathrm{yn}-210 \mathrm{~mm}, \mathrm{Rx}-17 \mathrm{~mm}$

$\square-\mathrm{G}=50 \mathrm{~mm}, \mathrm{yn}=180 \mathrm{~mm}, \mathrm{Rx}=52 \mathrm{~mm}$

$-\square-\mathrm{G}=70 \mathrm{~mm}, \mathrm{yn}=180 \mathrm{~mm}, \mathrm{Rx}=17 \mathrm{~mm}$

$-\mathrm{G}=70 \mathrm{~mm}, \mathrm{yn}=180 \mathrm{~mm}, \mathrm{Rx}=35 \mathrm{~mm}$

- $\mathrm{G}=70 \mathrm{~mm}, \mathrm{yn}=180 \mathrm{~mm}, \mathrm{Rx}=52 \mathrm{~mm}$

$\leftarrow \mathrm{G}=90 \mathrm{~mm}, \mathrm{ym}=180 \mathrm{~mm}, \mathrm{Rx}=17 \mathrm{~mm}$

$-\mathrm{x}-\mathrm{G}=90 \mathrm{~mm}, \mathrm{yn}=180 \mathrm{~mm}, \mathrm{Rx}=35 \mathrm{~mm}$

$\Delta \mathrm{G}=90 \mathrm{~mm}, \mathrm{yn}=180 \mathrm{~mm}, \mathrm{Rx}=52 \mathrm{~mm}$

$\cdots-\mathrm{G}=\mathrm{N} / \mathrm{A}, \mathrm{Rx}=\mathrm{N} / \mathrm{A}$

\section{شكل V. يروفيل آبشستخى مدل پايه پِل مربعى با زبرى مستطيلى نا يِيوسته}

مستطيلى بهمراتب تأثير بيشـترى بـر كـاهش ميـزان آبشستـى مسى

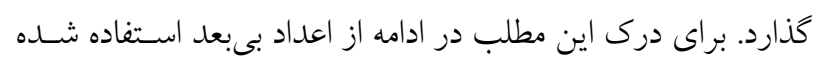
است كه در زير بخش مربوطـهـ بـــان اشـاره مسىشـود. بـا مقايسـهـ

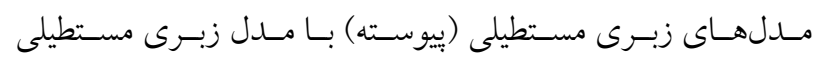

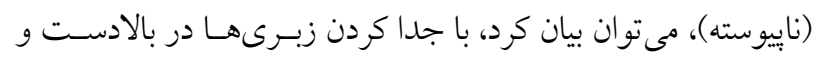
پاييندست، يِيشبينى مىشود، جت بيايينرونده كه در قالب جريـان

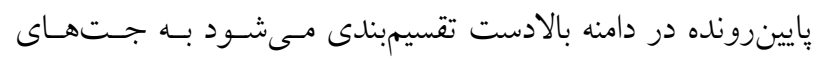
كو جكىتر تقسيمبندى شود. برخـورد جـتــهـاى بـايين رونـده در فواصل خالى زبرى-هاى نصب شده در وجه بالادست بايسه-ى يـل

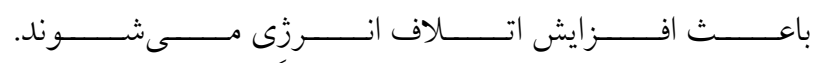

مى گذارد كه به خودى خود باعث كاهش آبشستخى مسىشود. همجنين افزايش طول زبرى در مدل زبرى مستطيلى بيوسـته تـا ه در صد باعث كاهش آبشستخى مسى شـود. درحسالى كـه ايسن كاهش بهازاى افزايش فاصله بين زبرىها بهمراتب كمتر بـوده و مقدار در حدود 11 درصد تخمين زده مىشود. مدل زبرى مستطيلى با زبرى ناييوسته: در ادامه، با هدف تعيـين

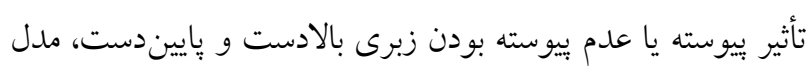

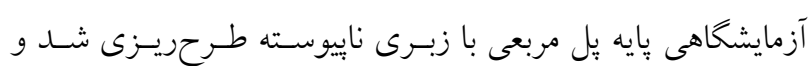

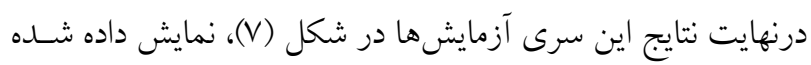

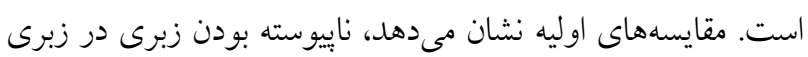



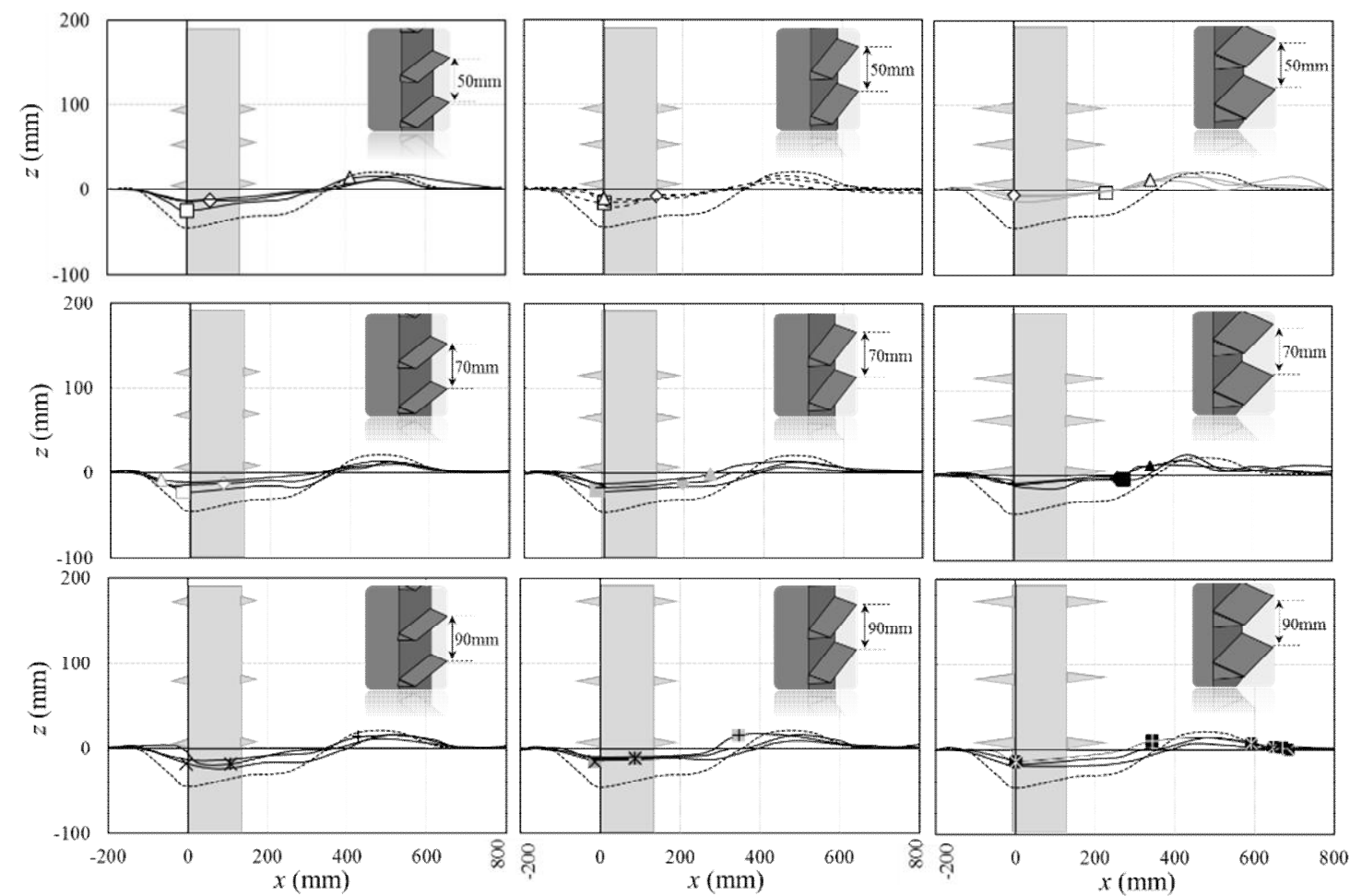

$-\square-\mathrm{G}=50 \mathrm{~mm}, \mathrm{yn}=180 \mathrm{~mm}, \mathrm{Rx}=17 \mathrm{~mm}$ $-\square-\mathrm{G}=50 \mathrm{~mm}, \mathrm{yn}=180 \mathrm{~mm}, \mathrm{Rx}=35 \mathrm{~mm}$ $\diamond \mathrm{G}=50 \mathrm{~mm}, \mathrm{yn}=200 \mathrm{~mm}, \mathrm{Rx}=52 \mathrm{~mm}$ $-\checkmark \mathrm{G}=70 \mathrm{~mm}, \mathrm{yn}=200 \mathrm{~mm}, \mathrm{Rx}=17 \mathrm{~mm}$ $-\rightarrow-G=70 \mathrm{~mm}, y n=200 \mathrm{~mm}, \mathrm{Rx}=35 \mathrm{~mm}$

$\bullet-\mathrm{G}=70 \mathrm{~mm}, \mathrm{yn}=200 \mathrm{~mm}, \mathrm{Rx}=52 \mathrm{~mm}$ $* \mathrm{G}=90 \mathrm{~mm}, \mathrm{yn}=200 \mathrm{~mm}, \mathrm{Rx}=17 \mathrm{~mm}$ $-*-\mathrm{G}=90 \mathrm{~mm}, \mathrm{yn}=200 \mathrm{~mm}, \mathrm{Rx}=35 \mathrm{~mm}$ $\rightarrow \&-G=90 \mathrm{~mm}, \mathrm{yn}=200 \mathrm{~mm}, \mathrm{Rx}=52 \mathrm{~mm}$

$\checkmark-\mathrm{G}=50 \mathrm{~mm}, \mathrm{yn}=200 \mathrm{~mm}, \mathrm{Rx}=17 \mathrm{~mm}$ $-\diamond-\mathrm{G}=50 \mathrm{~mm}, \mathrm{yn}=200 \mathrm{~mm}, \mathrm{Rx}=35 \mathrm{~mm}$ $\triangle \mathrm{G}=50 \mathrm{~mm}, \mathrm{yn}=210 \mathrm{~mm}, \mathrm{Rx}=52 \mathrm{~mm}$ $\rightarrow \mathrm{G}=70 \mathrm{~mm}, \mathrm{yn}=210 \mathrm{~mm}, \mathrm{Rx}=17 \mathrm{~mm}$ $-\mathrm{G}=70 \mathrm{~mm}, \mathrm{yn}=210 \mathrm{~mm}, \mathrm{Rx}=35 \mathrm{~mm}$ $\leftarrow \mathrm{G}=70 \mathrm{~mm}, \mathrm{yn}=210 \mathrm{~mm}, \mathrm{Rx}=52 \mathrm{~mm}$ + $\mathrm{G}=90 \mathrm{~mm}, \mathrm{yn}=210 \mathrm{~mm}, \mathrm{Rx}=17 \mathrm{~mm}$ 廿 $\mathrm{G}=90 \mathrm{~mm}, \mathrm{yn}=210 \mathrm{~mm}, \mathrm{Rx}=35 \mathrm{~mm}$ I- $\mathrm{G}=90 \mathrm{~mm}, \mathrm{yn}=210 \mathrm{~mm}, \mathrm{Rx}=52 \mathrm{~mm}$ $-\triangle \mathrm{G}=50 \mathrm{~mm}, \mathrm{yn}=210 \mathrm{~mm}, \mathrm{Rx}=17 \mathrm{~mm}$ $\square-\mathrm{G}=50 \mathrm{~mm}, \mathrm{yn}=180 \mathrm{~mm}, \mathrm{Rx}=52 \mathrm{~mm}$ $--\mathrm{G}=70 \mathrm{~mm}, \mathrm{yn}=180 \mathrm{~mm}, \mathrm{Rx}=17 \mathrm{~mm}$ $-\mathrm{G}=70 \mathrm{~mm}, \mathrm{yn}=180 \mathrm{~mm}, \mathrm{Rx}=35 \mathrm{~mm}$ - $\mathrm{G}=70 \mathrm{~mm}, \mathrm{yn}=180 \mathrm{~mm}, \mathrm{Rx}=52 \mathrm{~mm}$ $* \mathrm{G}=90 \mathrm{~mm}, \mathrm{yn}=180 \mathrm{~mm}, \mathrm{Rx}=17 \mathrm{~mm}$ $-x-G=90 \mathrm{~mm}, y n=180 \mathrm{~mm}, \mathrm{Rx}=35 \mathrm{~mm}$ $\rightarrow \varangle-\mathrm{G}=90 \mathrm{~mm}, \mathrm{yn}=180 \mathrm{~mm}, \mathrm{Rx}=52 \mathrm{~mm}$ $\cdots \cdot \mathrm{G}=\mathrm{N} / \mathrm{A}, \mathrm{Rx}=\mathrm{N} / \mathrm{A}$

شكل ^^ـ يروفيل آبشستخى مدل پايه يٍل مربعى با زبرى مثلثى وييوسته

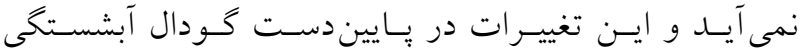
محسوستر است. بيان مىشود كه با تغييـر هندسـه زبـرى بـهـ خاطر شكل هندسى زبرى مثلثى و نزديـى بـودن بـه خطـوط جريان در حالـت جــايش جريـان در جـاييندسـت، جــدايش كمترى در مقايسه با مدل مستطيلى بهوجود خواهد آورد. ايسن

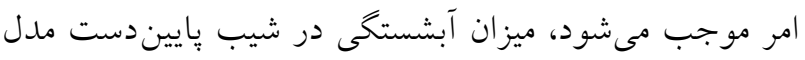

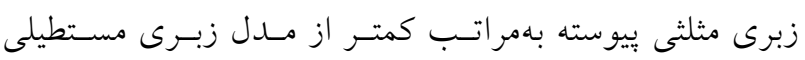
بيوسته باشد. با مقايسه شكل ل و 1 بهصورت نظيـر بـهـ نظيـر مىتوان اين مطلب را استنباط كرد. ملدل زبرى مثلثى ناييوسته: نتايج اين مدل نشان داد، بـا جـــا كردن زبرى مثلثى از حالت بيوسته به ناييوسته تغيير محسوسىى
باشد. درنهايت اين استهلاك باعث مىشود، جريان يايينرونــده با انرزى كمترى در دامنه بالادست يُايه يُل برخورد كند. اين امـر موجب مىشود، ميزان آبشستخى به مقدار محسوسى كاهش بيدا كند. - n مدل زبرى مثلثى با زبرى بيوسته: همجيْنين بـراى بررسـى،

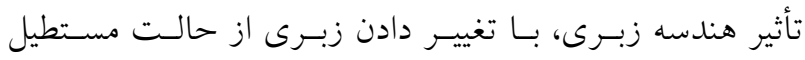
ييوسته به مثلث بيوسته، تأثير اين فاكتور نيز بررسى شد. نتايج اين مقايسه در شكل (N) نمايش داده شده است. مقايسـه بـين مدل آبشستخى زبرى مستطيلى بيوسته (شكل و) با مدل زبرى مثلثى، نشان مسىدهــ كـه بـا تغييـر هندســه زبــرى در دامنـــ بالادست و گودال آبشسته شده تغييـرات محسوسـى بـهورجـود 

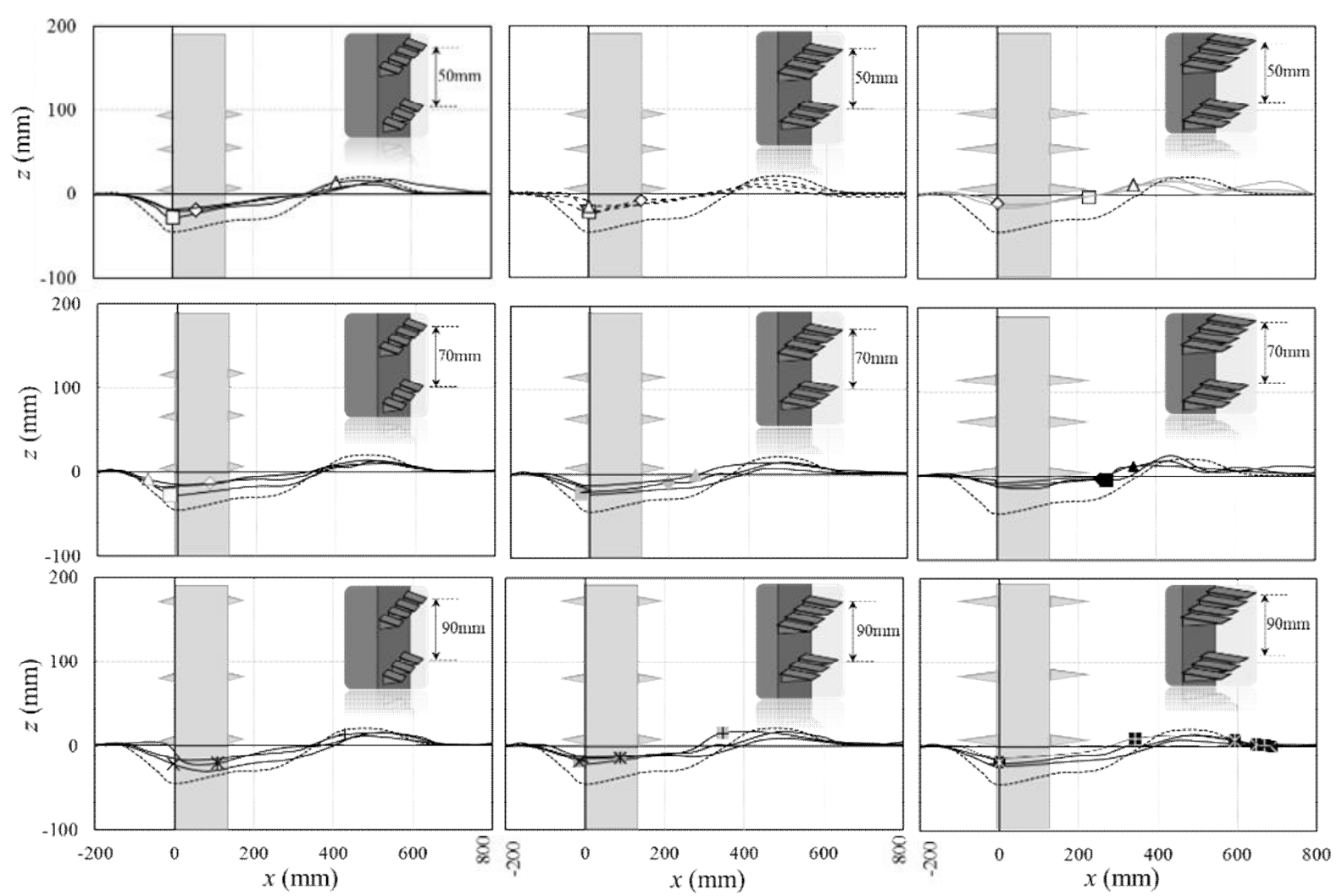

$-\square-G=50 \mathrm{~mm}, y n=180 \mathrm{~mm}, R x=17 \mathrm{~mm}$
$-\square-\mathrm{G}=50 \mathrm{~mm}, \mathrm{yn}=180 \mathrm{~mm}, \mathrm{Rx}=35 \mathrm{~mm}$
$\diamond-\mathrm{G}=50 \mathrm{~mm}, \mathrm{yn}=200 \mathrm{~mm}, \mathrm{Rx}=52 \mathrm{~mm}$
$-\mathrm{G}=70 \mathrm{~mm}, \mathrm{yn}=200 \mathrm{~mm}, \mathrm{Rx}=17 \mathrm{~mm}$
$-\mathrm{G}=70 \mathrm{~mm}, \mathrm{yn}=200 \mathrm{~mm}, \mathrm{Rx}=35 \mathrm{~mm}$
$-\mathrm{G}=70 \mathrm{~mm}, \mathrm{yn}=200 \mathrm{~mm}, \mathrm{Rx}=52 \mathrm{~mm}$
$* \mathrm{G}=90 \mathrm{~mm}, \mathrm{yn}=200 \mathrm{~mm}, \mathrm{Rx}=17 \mathrm{~mm}$
$-\mathrm{G}=90 \mathrm{~mm}, \mathrm{yn}=200 \mathrm{~mm}, \mathrm{Rx}=35 \mathrm{~mm}$
$\rightarrow-\mathrm{G}=90 \mathrm{~mm}, \mathrm{yn}=200 \mathrm{~mm}, \mathrm{Rx}=52 \mathrm{~mm}$

$\checkmark \mathrm{G}=50 \mathrm{~mm}, \mathrm{yn}=200 \mathrm{~mm}, \mathrm{Rx}=17 \mathrm{~mm}$ - $\diamond \cdot \mathrm{G}=50 \mathrm{~mm}, \mathrm{yn}=200 \mathrm{~mm}, \mathrm{Rx}=35 \mathrm{~mm}$ $\triangle \mathrm{G}=50 \mathrm{~mm}, \mathrm{yn}=210 \mathrm{~mm}, \mathrm{Rx}=52 \mathrm{~mm}$ $-\mathrm{G}=70 \mathrm{~mm}, \mathrm{yn}=210 \mathrm{~mm}, \mathrm{Rx}=17 \mathrm{~mm}$ $-\mathrm{G}=70 \mathrm{~mm}, \mathrm{yn}=210 \mathrm{~mm}, \mathrm{Rx}=35 \mathrm{~mm}$ $\star \mathrm{G}=70 \mathrm{~mm}, \mathrm{yn}=210 \mathrm{~mm}, \mathrm{Rx}=52 \mathrm{~mm}$ $+\mathrm{G}=90 \mathrm{~mm}, \mathrm{yn}=210 \mathrm{~mm}, \mathrm{Rx}=17 \mathrm{~mm}$ $+\mathrm{G}=90 \mathrm{~mm}, \mathrm{yn}=210 \mathrm{~mm}, \mathrm{Rx}=35 \mathrm{~mm}$ II- $\mathrm{G}=90 \mathrm{~mm}, \mathrm{yn}=210 \mathrm{~mm}, \mathrm{Rx}=52 \mathrm{~mm}$ $-\triangle \mathrm{G}=50 \mathrm{~mm}, \mathrm{yn}=210 \mathrm{~mm}, \mathrm{Rx}=17 \mathrm{~mm}$ $\square-\mathrm{G}=50 \mathrm{~mm}, \mathrm{yn}=180 \mathrm{~mm}, \mathrm{Rx}=52 \mathrm{~mm}$ $-\mathrm{G}=70 \mathrm{~mm}, \mathrm{yn}=180 \mathrm{~mm}, \mathrm{Rx}=17 \mathrm{~mm}$ -iㅣㄹ $-\mathrm{G}=70 \mathrm{~mm}, \mathrm{yn}=180 \mathrm{~mm}, \mathrm{Rx}=35 \mathrm{~mm}$ - $-\mathrm{G}=70 \mathrm{~mm}, \mathrm{yn}=180 \mathrm{~mm}, \mathrm{Rx}=52 \mathrm{~mm}$ $\star \mathrm{G}=90 \mathrm{~mm}, \mathrm{yn}=180 \mathrm{~mm}, \mathrm{Rx}=17 \mathrm{~mm}$ $-\mathrm{x}-\mathrm{G}=90 \mathrm{~mm}, \mathrm{yn}=180 \mathrm{~mm}, \mathrm{Rx}=35 \mathrm{~mm}$ $\rightarrow-G=90 \mathrm{~mm}, \mathrm{yn}=180 \mathrm{~mm}, \mathrm{Rx}=52 \mathrm{~mm}$ ….. $\mathrm{G}=\mathrm{N} / \mathrm{A}, \mathrm{Rx}=\mathrm{N} / \mathrm{A}$

$$
\text { شكل 9. بروفيل آبشستخى مدل بايه يل مربعى با زبرى مثلثى ناييوسته }
$$

مدلهاى زبرى مستطيلى بيوسته، مدهاى زبرى مستطيلى ناييوسته،

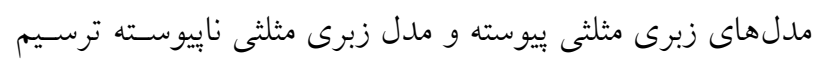

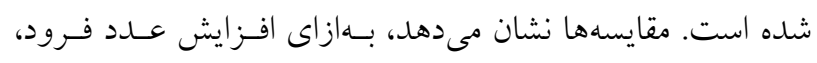

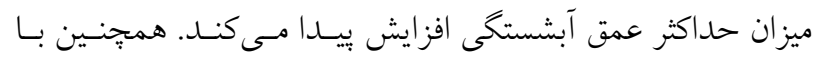

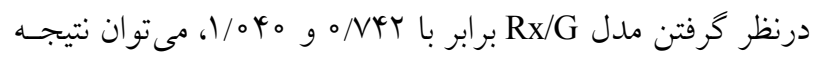

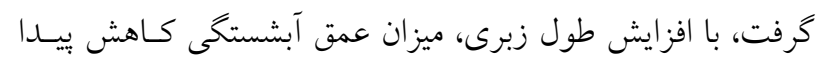

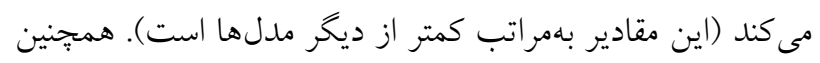

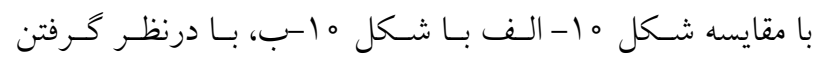

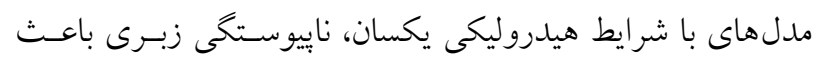

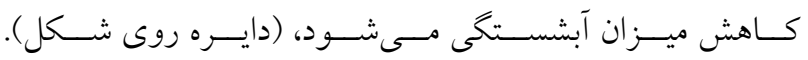

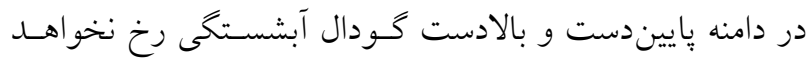

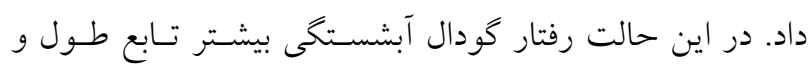

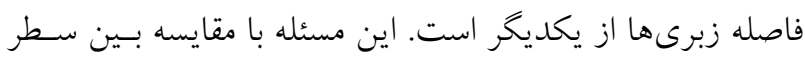

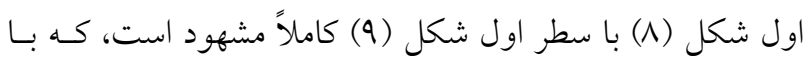

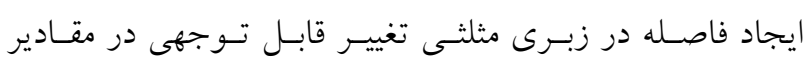
آبشستخى مشخص نيست.

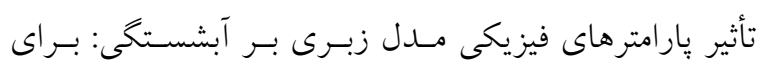

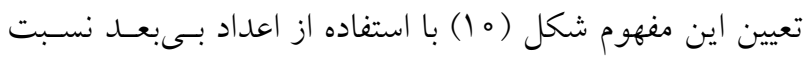

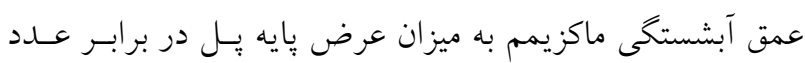

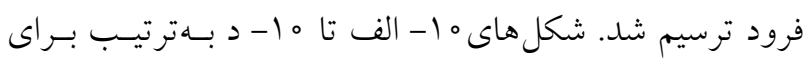




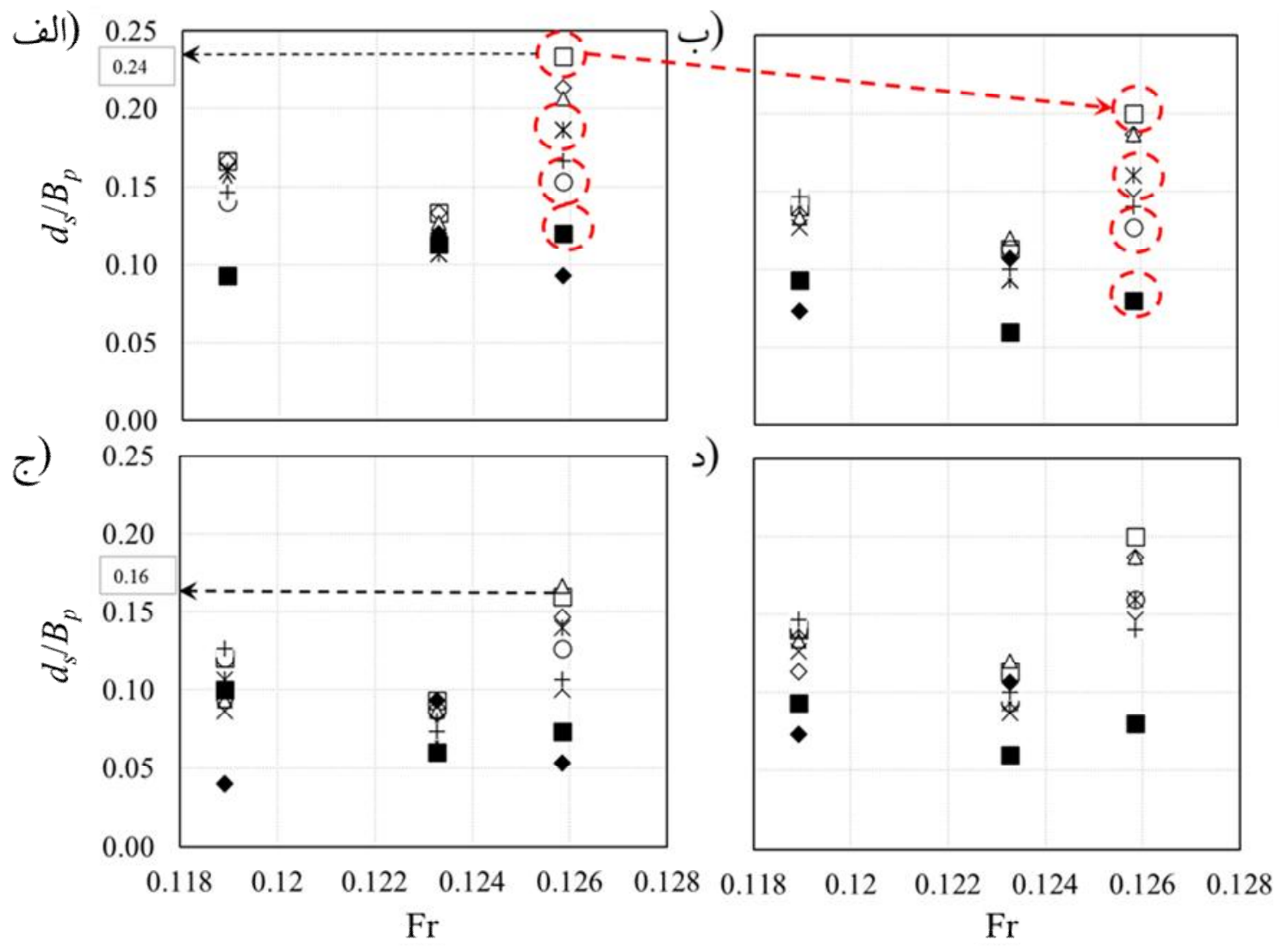

$\square \mathrm{Rx} / \mathrm{G}=0.188 \diamond \mathrm{Rx} / \mathrm{G}=0.242 \Delta \mathrm{Rx} / \mathrm{G}=0.340 \times \mathrm{Rx} / \mathrm{G}=0.389 * \mathrm{Rx} / \mathrm{G}=0.500$
$\mathrm{Rx} / \mathrm{G}=0.577+\mathrm{Rx} / \mathrm{G}=0.700 \quad \mathrm{Rx} / \mathrm{G}=0.742 \bullet \mathrm{Rx} / \mathrm{G}=1.040$

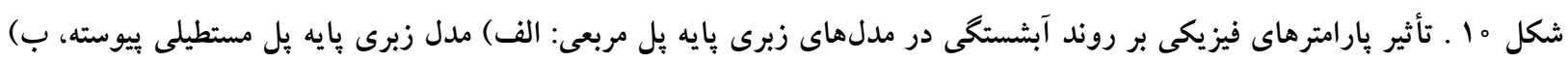

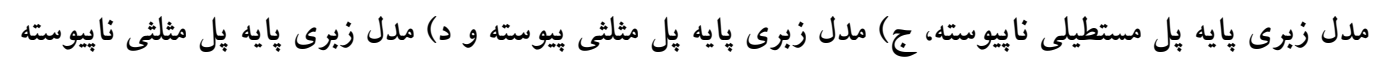

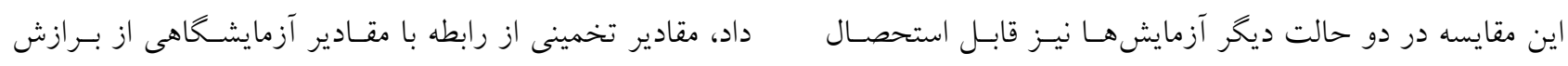

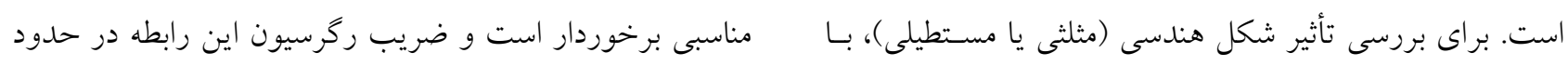

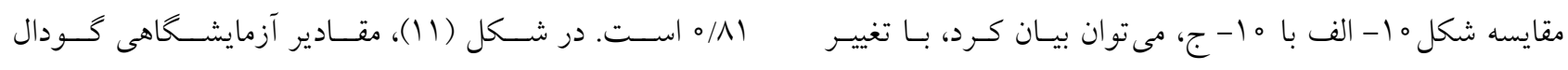

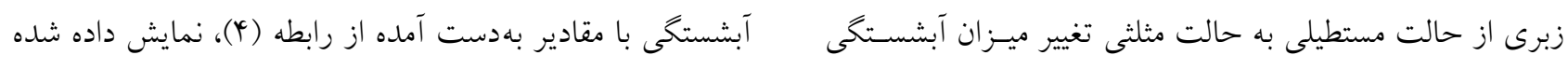
ماكزيمم به ميزان زيادى كاهش بيدا مي كند. $\frac{\mathrm{d}_{\mathrm{s}}}{\mathrm{B}_{\mathrm{p}}}=\mathrm{f}\left(\mathrm{Fr}, \frac{\mathrm{R}_{\mathrm{x}}}{\mathrm{G}}, \frac{\mathrm{d}_{50}}{\mathrm{y}}\right)$

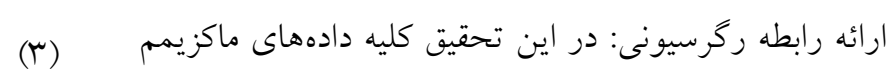
$\frac{\mathrm{d}_{\mathrm{s}}}{\mathrm{B}_{\mathrm{p}}}=\frac{1}{3}\left[0.32 \mathrm{Fr}^{0.11}-1.52\left(\frac{\mathrm{R}_{\mathrm{x}}}{\mathrm{G}}\right)^{0.121}+\left(\frac{\mathrm{d}_{50}}{\mathrm{y}}\right)^{0.12}+1.05\right]$

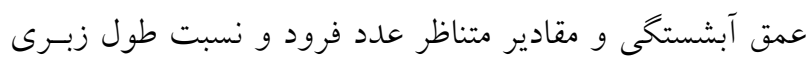

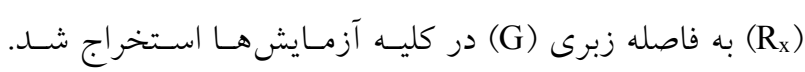

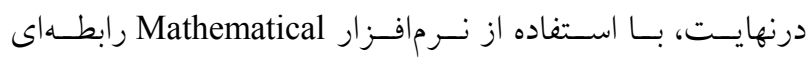

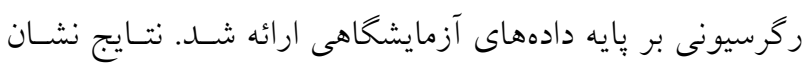




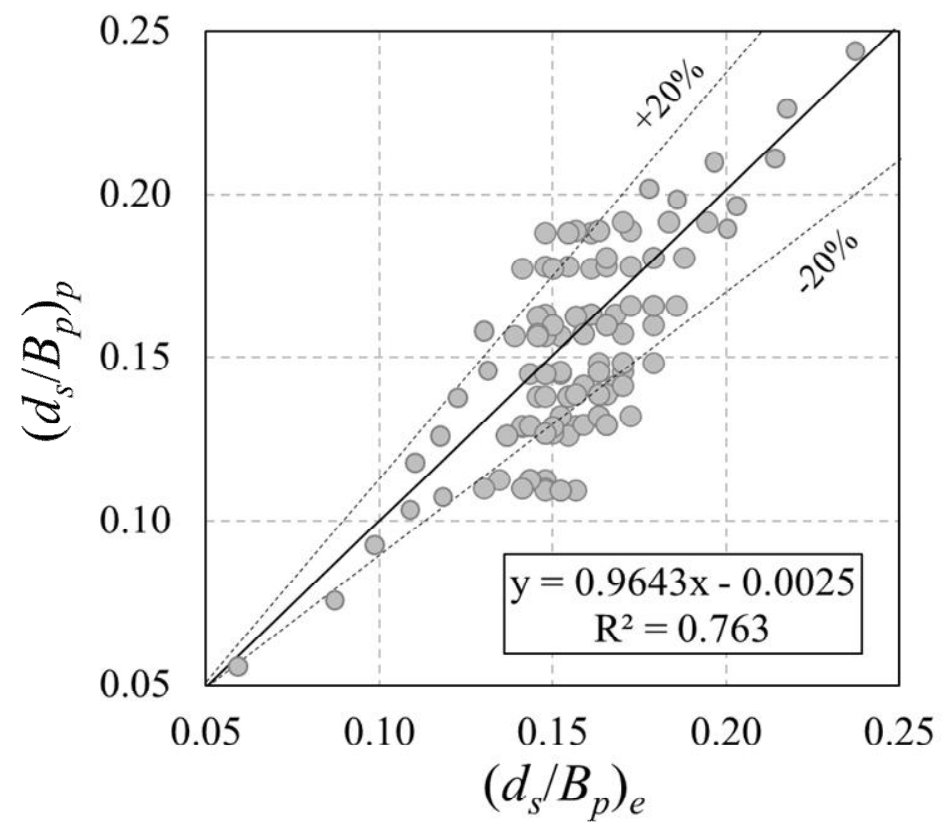

شكل 11. ميزان دقت رابطه ارائه شده

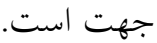

r-مقايسههاى بـين مــلهــاى ييوسـته و ناييوسـته بيـانكر ايسن

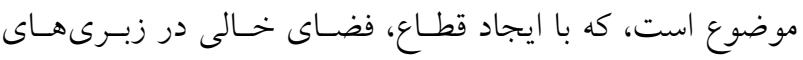

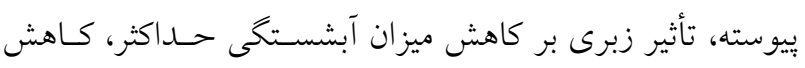

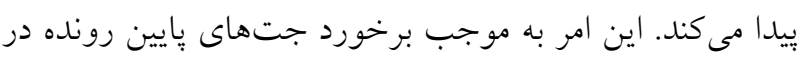

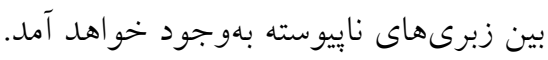

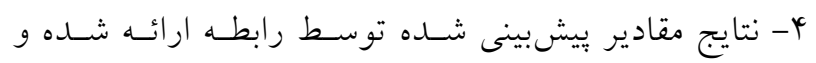

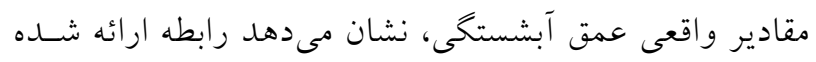

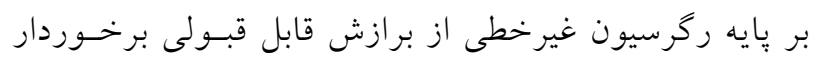

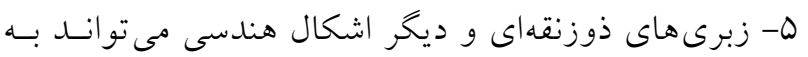

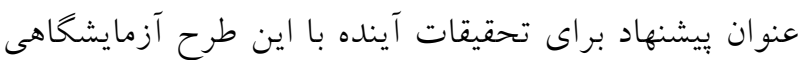

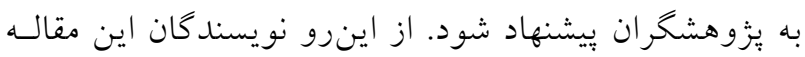

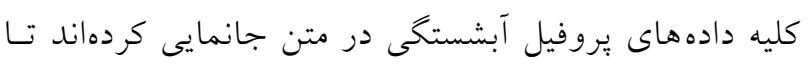

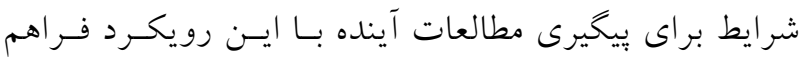
شود. - مان.

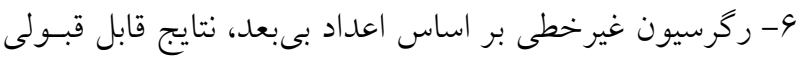

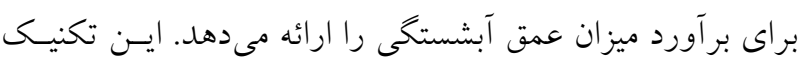

\section{نتيجه گيرى}

در اين بخش به نتايج حاصل از ايسن تحقيـق بـهصورت مـورد

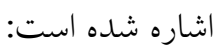
ا-نتايج حاصل از مقايسه مدل آبشستخى مدل زبرى مستطيلى

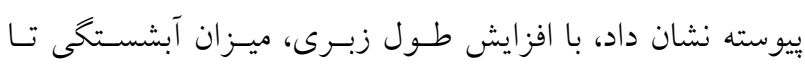

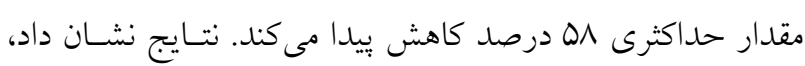

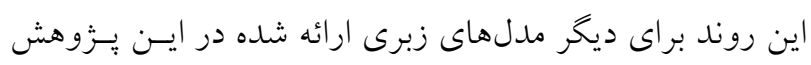

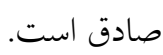
r- افزايش فاصله بين زبرىهاى مدل آبشستخى تأثير مستقيم

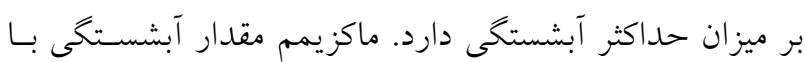

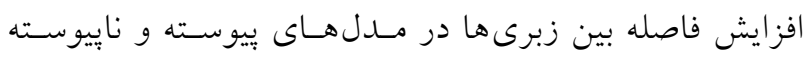

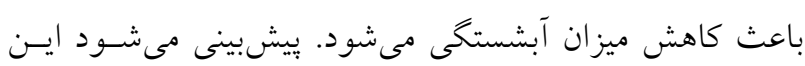

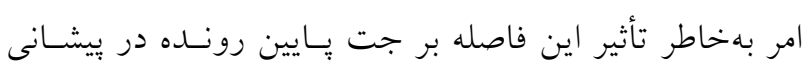

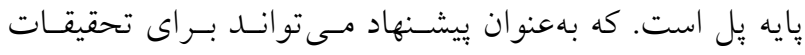

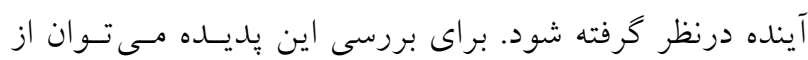

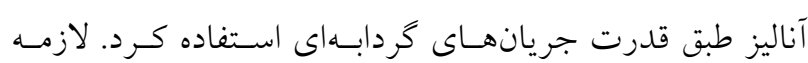

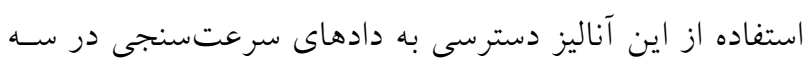




$$
\begin{aligned}
& \text { شسته شدن رسوبات بررسى كرد. } \\
& \text { مىتواند براى ديخر مباحث هيدروليك استفاده شود (19). }
\end{aligned}
$$

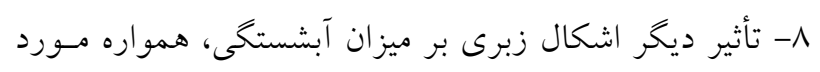

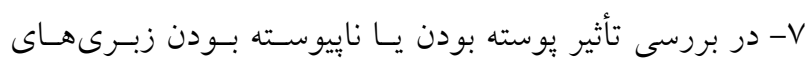

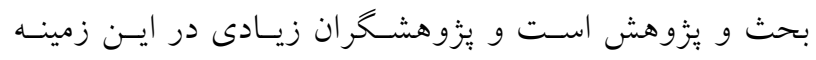

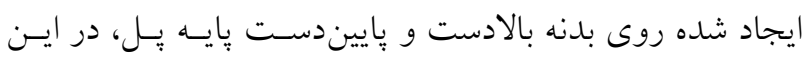

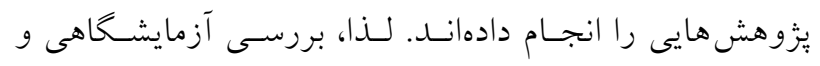

$$
\begin{aligned}
& \text { عددى اثر شكل زبرى را مى توان، براى تحقيقات آينده بيشنهاد إنهاد }
\end{aligned}
$$

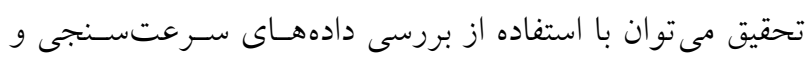

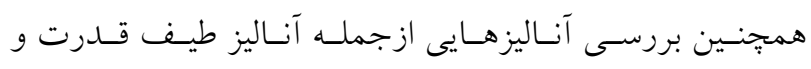

$$
\begin{aligned}
& \text { كرد. }
\end{aligned}
$$

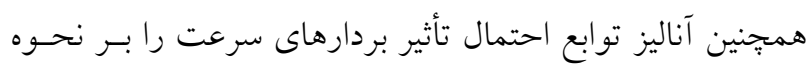

\section{منابع مورد استفاده}

1. Ahmadi, A., M. Heidarpour and H. Shahsavari. 2017. The effect of roughness protrusions in reducing scour around bridge piers and its impact on the vertical velocity profile. Journal of Water and Soil Conservation. 10.22069/JWFST.2017.9886.2424.

2. Amini, A., B. W. Melville, T. M. Ali and A. H. Ghazali. 2011. Clear-water local scour around pile groups in shallow-water flow. Journal of Hydraulic Engineering 138(2): 177-185.

3. Ataie-Ashtiani, B. and A. A. Beheshti. 2006. Experimental investigation of clear-water local scour at pile groups. Journal of Hydraulic Engineering 132(10): 1100-1104.

4. Barkdoll, B. B., B. W. Melville and Y. M. Chiew. 2000. Time scale for local scour at bridge piers. Journal of Hydraulic Engineering 126(10): 793-795.

5. Bayram, A. and M. Larson. 2000. Analysis of scour around a group of vertical piles in the field. Journal of Waterway, Port, Coastal, and Ocean Engineering 126(4): 215-220.

6. Beheshti, A. A. and B. Ataie-Ashtiani. 2010. Experimental study of three-dimensional flow field around a complex bridge pier. Journal of Engineering Mechanics 136(2): 143-154.

7. Beheshti, A. A. and B. Ataie-Ashtiani. 2016. Scour hole influence on turbulent flow field around complex bridge piers. Flow Turbulence and Combustion 97: 6.

8. Bestawy, A., T. Eltahawy, A. Alsaluli, A. Almaliki and M. Alqurashi. 2020. Reduction of local scour around a bridge pier by using different shapes of pier slots and collars. Water Supply 20(3): 1006-1015.

9. Breisers, H. N. C. and A. J. Raudkivi. 1991. Scouring. $2^{\text {nd }}$ Hydraulic Structures Design Manual, IAHR, A. A. Balkema, Roterdam, The Netherlands.

10. Dey, S., B. M. Sumer and J. Fredsøe. 2006. Control of scour at vertical circular piles under waves and current. Journal of Hydraulic Engineering 132(3): 270-279.

11. Ettema, R., G. Kirkil and M. Muste. 2006. Similitude of large-scale turbulence in experiments on local scour at cylinders. Journal of Hydraulic Engineering 132(1): 33-40.

12. Farooq, R., A. R. Ghumman, M. A. U. R. Tariq, A. Ahmed and K. Z. Jadoon. 2020. Optimal octagonal hooked collar countermeasure to reduce scour around a single bridge pier. Periodica Polytechnica Civil Engineering 64(4): 1026-1037.

13. Hannah, C. R. 1978. Scour at pile groups. Research Rep. No. 78-3. Department of Civil Engineering, University of Canterbury, New Zealand.

14. Heidarpour, M., H. Afzalimehr and Z. Khodarahmi. 2007. Local scour protection of circular bridge pier groups using slot. Journal of Agricultural Sciences and Natural Resources 14(3):174-185. (in Farsi).

15. Lança, A. R., C. Fael, R. Maia, J. P. Pêgo and H. Cardoso. 2013a. Clear-water scour at pile groups. Journal of Hydraulic Engineering 139(10):1089-1098.

16. Melville, B. W. and Y. M. Chiew. 1999. Time scale for local scour at bridge piers. Journal of Hydraulic Engineering 125(1): 59-65.

17. Memar, S., M. Zounemat-Kermani, A. Beheshti, M. Rahimpour, G. De Cesare and A. J. Schleiss. 2020. Influence of collars on reduction in scour depth at two piers in a tandem configuration. Acta Geophysica 68(1): 229-242.

18. Nordila, A., M. Thamer, B. W. Melville, A. Faisal and Y. Badronnisa. 2017. Modelling the effect of sediment coarseness on local scour at wide bridge piers. Pertanika Journal of Social Science and Humanities 25(1): $191-200$.

19. Pagliara, S., I. Carnacina and F. Cigni. 2010. Sills and gabions as countermeasures at bridge pier in presence of debris accumulations. Journal of Hydraulic Research 48(6): 764-774.

20. Saadati Pachekenari, S. S., M. Esmaeili Varaki and R. Fazl Ola. 2014. Experimental investigation of effect of sill location on local scour around inclined bridge piers group. Journal of Water and Soil 28(2): 406-419. (in Farsi). 
21. Salehi, S. and A. H. Azimi. 2019. Discharge characteristics of weir-orifice and weir-gate structures. Journal of Irrigation and Drainage Engineering 145(11): 04019025.

22. Zarrati, A. R., M. Nazariha and M. B. Mashahir. 2006. Reduction of local scour in the vicinity of bridge pier groups using collars and riprap. Journal of Hydraulic Engineering 132(2): 154-162. 


\title{
Effect of Upstream and Downstream Roughness on Scour Hole of Square Bridge Pile
}

\author{
H. Kazemizadeh ${ }^{1}$, M. Saneie ${ }^{1,2 *}$ and H. Haji Kandi ${ }^{3}$
}

(Received: March 18-2020; Accepted: October 28-2020)

\begin{abstract}
To prevent demolishing bridge piles due to developing the scour hole under the foundation of these piles some solution has been proposed in the literature. One of the important approaches could be installing different geometric of roughness at the downstream and upstream piles sections. This causes the downward flows which are performing the main role in developing scour holes to be marginally decreased. The present study explores the effect of geometric roughness and also, continuity and un-continuity of roughness length on maximum scour holes around bridge pile. Results indicate that due to increasing the length of roughness the developed scour holes were formed by less scour hole depths. Furthermore, continuity of roughness increases the scour hole depths; however, un-continuity causes the height of scour holes to be developed by fewer values. Also, the comparison shows that the length of installed roughness in maximum value is decreasing the scour hole depth constitute 34 percent. Based on the non-linear regression technique an equation has been proposed to predict the maximum scour hole due to different conditions. Comparison between experimental and proposed values shows that the accuracy of the proposed equation has an acceptable error which has been calculated less than 11 percent.
\end{abstract}

Keywords: Scour hole, Squire bridge pile, Rectangular roughness, Triangular roughness, Non-liner regression, Analytical solution

1. Department of Water Civilis Engineering, NajafAbad Branch, Islamic Azad University, NajafAbad, Iran 2. Soil Conservation and Watershed Management, Research Institute Tehran University, Tehran, Iran.

3. Department of Water Civilis Engineering, Central Tehran Branch, Islamic Azad University, Tehran, Iran. Corresponding author, Email: saneie_m@scwmri.ac.ir 